\title{
Limitations of WRF land surface models for simulating land use and land cover change in Sub-Saharan Africa and development of an improved model (CLM-AF v. 1.0)
}

\author{
Timothy Glotfelty ${ }^{1}$, Diana Ramírez-Mejía ${ }^{2}$, Jared Bowden ${ }^{3}$, Adrian Ghilardi ${ }^{2}$, and J. Jason West ${ }^{1}$ \\ ${ }^{1}$ Department of Environmental Sciences and Engineering, University of North Carolina at Chapel Hill, \\ Chapel Hill, NC 27599, USA \\ ${ }^{2}$ Centre for Research in Environmental Geography, Universidad Nacional Autónoma de México, Morelia, 58190, Mexico \\ ${ }^{3}$ Department of Applied Ecology, North Carolina State University, Raleigh, NC 27695, USA
}

Correspondence: Timothy Glotfelty (twglotfe@email.unc.edu)

Received: 12 June 2020 - Discussion started: 19 August 2020

Revised: 25 March 2021 - Accepted: 18 April 2021 - Published: 3 June 2021

\begin{abstract}
Land use and land cover change (LULCC) impacts local and regional climates through various biogeophysical processes. Accurate representation of land surface parameters in land surface models (LSMs) is essential to accurately predict these LULCC-induced climate signals. In this work, we test the applicability of the default Noah, Noah-MP, and Community Land Model (CLM) LSMs in the Weather Research and Forecasting (WRF) model over Sub-Saharan Africa. We find that the default WRF LSMs do not accurately represent surface albedo, leaf area index, and surface roughness in this region due to various flawed assumptions, including the treatment of the MODIS woody savanna land use and land cover (LULC) category as closed shrubland. Consequently, we developed a WRF CLM version with more accurate African land surface parameters (CLM-AF), designed such that it can be used to evaluate the influence of LULCC. We evaluate meteorological performance for the default LSMs and CLM-AF against observational datasets, gridded products, and satellite estimates. Further, we conduct LULCC experiments with each LSM to determine if differences in land surface parameters impact the LULCCinduced climate responses. Despite clear deficiencies in surface parameters, all LSMs reasonably capture the spatial pattern and magnitude of near-surface temperature and precipitation. However, in the LULCC experiments, inaccuracies in the default LSMs result in illogical localized temperature and precipitation changes. Differences in thermal changes between Noah-MP and CLM-AF indicate that the temper-
\end{abstract}

ature impacts from LULCC are dependent on the sensitivity of evapotranspiration to LULCC in Sub-Saharan Africa. Errors in land surface parameters indicate that the default WRF LSMs considered are not suitable for LULCC experiments in tropical or Southern Hemisphere regions and that proficient meteorological model performance can mask these issues. We find CLM-AF to be suitable for use in Sub-Saharan Africa LULCC studies, but more work is needed by the WRF community to improve its applicability to other tropical and Southern Hemisphere climates.

\section{Introduction}

Land use and land cover change (LULCC) has various biogeophysical impacts on climate by altering land surface albedo, evapotranspiration, and surface roughness that in turn alter atmospheric circulations, energy budgets, and hydrologic cycles (Pielke et al., 2011; Mahmood et al., 2014; Bright, 2015; Smith et al., 2016; Quesada et al., 2017). Results from global modeling studies indicate a global reduction in surface temperatures due to deforestation, but the impacts of LULCC vary by region and season (e.g., Zhao and Pitman, 2002; Lamptey et al., 2005; Lejeune et al., 2017). Such studies have shown a latitudinal difference in the temperature response to deforestation, where higher latitudes experience cooling in winter as less tree cover brightens the surface when snow is present, and lower-latitude tropical re- 
gions experience warming in response to a reduction in evaporation (e.g., Longobardi et al., 2016; Quesada et al., 2017). This LULCC latitudinal dependence has been shown to occur in observations as well (Zhang et al., 2014).

Impacts of LULCC are simulated in climate and numerical weather prediction models through a land surface model (LSM). Differences in LSM parameterizations can lead to significantly different simulated climate responses to LULCC in both magnitude and sign (e.g., Olsen et al., 2004; Boisier et al., 2012; Burakowski et al., 2016), even when little difference exists in the mean simulated climate (Crossley et al., 2000). Errors and uncertainties in LSMs occur in response to errors in land use and land cover (LULC) classification maps and in the prescription of land use properties, such as vegetation distributions and surface albedo (e.g., Lu and Shuttleworth, 2002; Olsen et al., 2004; Ge et al., 2007; Boisier et al., 2012, 2013; Boysen et al., 2014; Meng et al., 2014; Hartley et al., 2017; Bright et al., 2018). As a result, improving LULC maps and LSM parameters has been shown to significantly reduce biases and errors within global and regional climate models (RCMs) (e.g., Tian et al., 2004b; Kang et al., 2007; Lawrence and Chase, 2007, 2009; Moore et al., 2010; Karri et al., 2016; Thackeray et al., 2019). Having accurate representations of these parameters is especially important in regions with widespread surface heterogeneity, such as East Africa (Ge et al., 2008).

Sub-Saharan Africa is a region of particular interest for simulating LULCC because it has already experienced dramatic LULCC (e.g., Collier et al., 2008), which has been shown to alter the West African monsoon system (e.g., Charney, 1975; Xue and Shukla, 1993; Abiodun et al., 2008; Wang et al., 2017). Various ensembles of RCMs have been applied to study the climate of Africa as part of both the COordinated Regional climate Downscaling Experiment (CORDEX) (e.g., Nikulin et al., 2012; Gbobaniyi et al., 2014; Kim et al., 2014; Mounkaila et al., 2015; Endris et al., 2016; Diasso and Abiodun, 2017; Adeniyi and Dilau, 2018; Odoulami et al., 2019) and the West African Monsoon Modeling and Evaluation Project Experiments (WAMME) (e.g., Wang et al., 2016; Xue et al., 2016). Included as part of these ensemble modeling projects is the Weather Research and Forecasting (WRF) model (e.g., Xue et al., 2016; Fita et al., 2019).

The WRF model is a state-of-the-art numerical weather prediction model designed to be applicable in multiple world regions, across multiple spatial scales, and for both shortterm forecasting and longer-term regional climate simulations (Skamarock and Klemp, 2008). Multiple studies have tested the sensitivity of the African climate to different ensembles of WRF physics parameterizations, including LSMs (e.g., Pohl et al., 2011; Hagos et al., 2014; Noble et al., 2014; Alaka and Maloney, 2017; Noble et al., 2017; Igri et al., 2018). Results from these WRF simulations are somewhat contradictory, as some studies found the National Centers for Environmental Prediction, Oregon State University, Air
Force and Hydrology Lab (Noah) LSM (Chen and Dudhia, 2001; Ek et al., 2003) to have superior performance compared to observations and reanalyses (Pohl et al., 2011; Igri et al., 2018), while others found no unambiguous difference in model performance between different LSMs (Noble et al., 2014, 2017). In terms of LULCC applications, Hagos et al. (2014) found that WRF model configurations that simulate a climate which is too wet or too dry compared to observations and reanalysis do not produce a strong climate signal from LULCC over Africa. This weak signal is a result of the model falling into erroneous moisture- or energy-limited regimes. Despite these uncertainties, the Noah LSM is by far the most common LSM configuration applied in WRF studies over Africa (e.g., Vigaud et al., 2011; Cretat et al., 2012; Boulard et al., 2013; Ratna et al., 2014; Argent et al., 2015; Diaz et al., 2015; Klein et al., 2015; Schepanski et al., 2015; Zheng et al., 2015; Arnault et al., 2016; Kerandi et al., 2017; Klein et al., 2017).

In this work, we expand upon the current literature by testing five different LSM configurations within the WRF model for the purpose of evaluating the effects of LULCC over time on regional climate in Sub-Saharan Africa. First, we review four commonly used LSMs to determine if the LSM configurations reasonably represent land surface parameters such as albedo and leaf area index (LAI). As shown below, we find that these four LSMs have significant deficiencies that limit their capabilities in applications to LULCC in this region. Consequently, we then detail how we modify one LSM for use in this study. We then evaluate the five WRF LSM configurations against available meteorological observations, reanalysis, and satellite estimates to determine how well they simulate the current climate of Sub-Saharan Africa. To the authors' knowledge, this is the first time the surface parameters of these LSMs have been robustly assessed in SubSaharan Africa. Finally, we simulate the effects of LULCC over time on the simulated regional climate and how these climate responses differ when using different LSMs. Understanding the deficiencies in how LSMs represent LULCC is key to accurately representing regional climate signals that impact not only climate change investigations but also coupled natural and human system research regarding human decision-making, air quality, and human-ecosystem health interactions.

\section{WRF description and configurations}

This study uses the WRF model version 3.9.1.1 (WRFv3.9.1.1), configured as shown in Table 1, to simulate the regional meteorology and climate within Sub-Saharan Africa. We define a Sub-Saharan Africa domain that ranges from $\sim 19^{\circ} \mathrm{N}-35^{\circ} \mathrm{S}$ in latitude and $\sim 19^{\circ} \mathrm{W}-64^{\circ} \mathrm{E}$ in longitude (Fig. 1) with a horizontal grid spacing of $36 \mathrm{~km}$ and 30 vertical layers from the surface to $50 \mathrm{hPa}$. Physics parameterizations common to all simulations include the 
Table 1. Model configurations.

\begin{tabular}{ll}
\hline Simulation configuration & Setting \\
\hline Domain & Sub-Saharan Africa \\
Horizontal resolution & $36 \mathrm{~km}$ \\
Vertical layers & 30 layers from the surface to 50 hPa \\
Initial/boundary conditions & ERA-Interim (D11) \\
\hline Physics parameterization & Option \\
\hline Cumulus & New Tiedtke scheme (Z11) \\
Cloud microphysics & Aerosol-aware Thompson scheme (TE14) \\
Radiation & RRTMG (C05; I08) \\
Planetary boundary layer & MYNN (NN04; NN06) \\
Surface layer & MYNN (NN04; NN06) \\
Land surface models & Noah (CD01; E03) \\
& Noah-MP (N11) \\
Lake model & CLM 4.5 (S11; JW12; LK12) \\
\hline
\end{tabular}

Acronyms are defined as follows: ERA-Interim: European Centre for Medium-Range Weather Forecasting Interim reanalysis; RRTMG: Rapid Radiative Transfer Model for General Circulation Models; MYNN: Mellor Yamada Nakanishi Niino; Noah: National Centers for Environmental Prediction, Oregon State University, Air Force, Hydrology Lab; Noah-MP: Noah Multi-parameterization options; CLM 4.5: Community Land Model version 4.5.

References are abbreviated as follows: D11: Dee et al. (2011); Z11: Zhang et al. (2011); TE14:

Thompson and Eidhammer (2014); C05: Clough et al. (2005); I08: Iacono et al. (2008); NN04:

Nakanishi and Niino (2004); NN06: Nakanishi and Niino (2006); CD01: Chen and Dudhia

(2001); E03: Ek et al. (2003); N11: Niu et al. (2011); S11: Subin et al. (2011); JW12: Jin and

Wen (2012); LK12: Lu and Kueppers (2012); S12: Subin et al. (2012); G15: Gu et al. (2015).

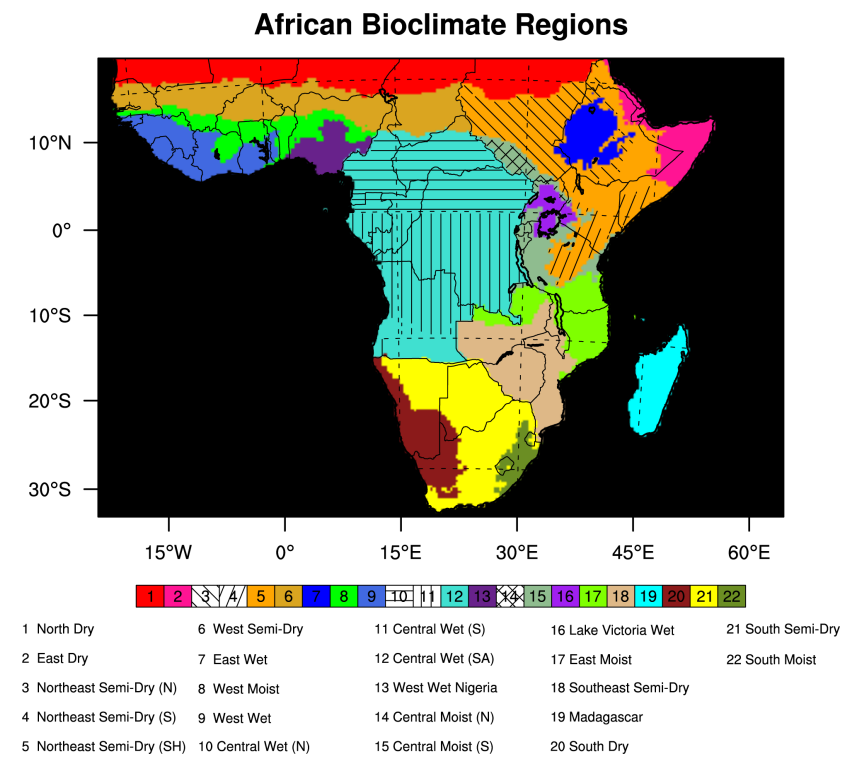

Figure 1. African bioclimate and sub-bioclimate regions defined in this study within the Sub-Saharan domain.

following schemes: the New Tiedtke cumulus parameterization scheme (Zhang et al., 2011), the aerosol-aware Thompson microphysics scheme (Thompson and Eidhammer, 2014), the RRTMG longwave and shortwave radiation schemes (Clough et al., 2005; Iacono et al., 2008), and the MYNN surface and planetary boundary layer physics schemes (Nakanishi and Niino, 2004, 2006). These physics combinations were selected because they represent some of the most advanced science within the WRF model, and these physics options performed the best when validated against observations and satellite estimates relative to other physics options tested (not shown). All simulations also take advantage of the Community Land Model 4.5 (CLM 4.5) lake model, which is calibrated to prognostically simulate lake conditions for the African Great Lakes by adjusting the lower bound lake temperature from 4 to $24^{\circ} \mathrm{C}$ consistent with Lake Victoria temperature profiles (Nyamweya et al. 2016). Meteorological initial and boundary conditions for the simulations are obtained from the European Centre for Medium-Range Weather Forecasts Interim reanalysis (ERA-Interim), with the variables used listed in Table S1 (Dee et al., 2011). Because LULC inputs change each year, every model year is simulated individually, preceded by a 3-month spin-up period that is discarded to allow the model to reach equilibrium and minimize the impact of initial conditions on the simulations.

\subsection{WRF land surface model descriptions}

Here we briefly describe four commonly-used WRF LSM configurations used in this study and differences between them: the Noah LSM, the Noah LSM using satellite-derived albedo and LAI (Noah-Sat), the Noah 
Multi-Parameterization LSM (Noah-MP) (Niu et al., 2011), and the default Community Land Surface model (CLM-D) (Subin et al., 2011; Jin and Wen, 2012; Lu and Kueppers, 2012). We focus on the different ways in which the LSMs prescribe and treat surface parameters such as LAI, albedo, and surface roughness length (RL) based on the Moderate Resolution Imaging Spectroradiometer (MODIS) 21 land category data. In addition to the LSMs used in this work, four other LSMs exist in WRF, including the five-layer thermal diffusion scheme (Skamarock and Klemp, 2008), the Rapid Update Cycle (RUC) LSM (Smirnova et al., 2016), the Pleim-Xiu (PX) LSM (Pleim and Xiu, 2003; Gilliam et al., 2007), and the Simplified Single Biosphere Model (SSiB) (Xue et al., 1991; Sun and Xue, 2001). The five-layer thermal diffusion scheme is omitted from these experiments because it is overly simplistic and not appropriate for climate-scale studies. The RUC and PX LSMs are primarily designed for weather forecasting and for retrospective meteorological simulations commonly used as input for downstream air quality simulations, respectively. Although RUC and PX can be used for other applications, they require extensive detailed input data or data assimilation for peak performance (https://www2.mmm.ucar.edu/wrf/users/docs/user_guide_ V3/user_guide_V3.9/users_guide_chap5.htm, last access: 20 May 2021). Since this detailed level of observational data is not available in Sub-Saharan Africa, both the RUC and PX scheme were excluded. The SSiB LSM is designed for climate applications; however, it is also excluded both because its best performance occurs using its own LULC dataset and because it is not currently compatible with the MYNN surface and boundary layer parameterizations.

\subsubsection{Noah LSM and Noah-Sat}

Noah and Noah-Sat are the same LSM with different configurations for how surface albedo and LAI are prescribed. Within the Noah LSM, surface parameters including surface albedo, RL, and LAI are prescribed based on the dominant MODIS LULC category in each grid cell with temporal interpolation between maximum and minimum values depending on the time of year. The Noah-Sat configuration uses a monthly average satellite-derived climatology of surface albedo and LAI supplied from the WRF preprocessing system (WPS) as a more detailed replacement of the LULCbased prescribed values. Noah and Noah-Sat have no explicit canopy layer and instead simulate evapotranspiration using a satellite-derived green fraction variable from WPS to weight the contribution of direct soil evaporation and evapotranspiration from vegetation in each grid cell. The land surface and underlying soil is simulated using 4 soil layers $0.1,0.3,0.6$, and $1.0 \mathrm{~m}$ thick centered at $0.05,0.25,0.7$, and $1.5 \mathrm{~m}$ below the ground surface, respectively.

Noah-Sat is limited in its ability to simulate LULCC because LAI and surface albedo are decoupled from changes in the LULC categories, and temporally varying satellite
LAI and albedo products are influenced by other climate variations or changes apart from effects of LULCC. Noah is also preferable to Noah-Sat for future climate simulations because the albedo and LAI products Noah-Sat requires would have to be generated as separate independently varying fields from the future LULC projection. However, NoahSat is useful for meteorological evaluation because it has the most accurate surface parameters in the current WRF modeling system. Therefore, Noah-Sat can be used as pseudoobservations to understand deficiencies in the surface parameter methodologies of the other WRF LSMs.

Additionally, the Noah LSM can be configured using a mosaic tile approach to represent the influence of sub-grid scale variations in LULC. The representation of sub-grid LULC variability can significantly alter the responses of climate models to LULCC (e.g., Boone et al., 2016), but this functionality is not considered in these experiments since any underlying errors in albedo, LAI, and RL within Noah would be present in both the mosaic tile and dominant LULC configurations. In addition, this approach has been shown to primarily impact urban regions (Mallard and Spero, 2019), which are not resolved well at the grid spacing of this study.

\subsubsection{Noah-MP}

The Noah-MP model is an updated version of the Noah LSM with multiple parameterization options utilizing the same soil level structure as the default Noah LSM. The major updates in Noah-MP include the addition of an explicit one-layer vegetation canopy and three-layer snowpack, a tiling scheme that separates vegetation and bare soil to better calculate the surface energy balance, separating permeable and impermeable frozen soils, new runoff and groundwater schemes, and new dynamic vegetation model options (Niu et al., 2011; Xia et al., 2017, and references therein). In this study, Noah-MP is configured with the default settings, which are the most similar to the default Noah LSM. With these default settings, dynamic vegetation is disabled and LAI is prescribed based on the dominant MODIS LULC category in each grid cell using monthly profile values. Noah-MP simulates surface reflectance using a modified two-stream radiation scheme that accounts for gaps within the vegetation canopy and between canopy crowns (Yang and Friedl, 2003; Niu and Yang, 2004); however, in WRFv3.9.1.1 Noah-MP uses a simplification that assumes all bare soil albedos are comparable to loam soil. As a result, surface albedo within Noah-MP is solely a function of soil moisture and vegetation cover.

\subsubsection{Default CLM (CLM-D)}

The default configuration of CLM in WRF divides the land surface into five types: glacier, lake, wetland, urban, and vegetated. Vegetated land is further split into up to four patches of 16 plant functional types (PFTs) with distinct physiological parameters. Calculations within each vegetated grid 
are done at the PFT level and then aggregated for atmosphere interactions. CLM contains a single-layer vegetation parametrization with a sunlit and shaded canopy and uses the two-stream approximation (Sellers, 1985) to calculate the energy balance within the canopy. Temperature and humidity varies between the ground surface, the canopy, and the leaf surface (Subin et al., 2011, and references therein). The land surface and soil properties in CLM are simulated using 10 layers $\sim 0.018,0.028,0.045,0.075,0.124,0.204,0.336$, $0.554,0.913$, and $1.134 \mathrm{~m}$ thick centered at $\sim 0.007,0.028$, $0.062,0.119,0.212,0.367,0.620,1.038,1.728$, and $2.86 \mathrm{~m}$ below the ground surface, respectively.

In the version of CLM available in WRF, each dominant MODIS land use category is assigned a distribution of PFTs with distinct monthly profiles for LAI that do not vary geographically. A list of the CLM PFTs with the percentages for each vegetated MODIS land use category is shown in Table S2 of the Supplement. Bare soil albedos in CLM are not constrained like within Noah-MP, and therefore a broader range of surface soil albedos is considered.

Some simplifications in WRF-CLM lead to difficulties applying the default version for the Sub-Saharan Africa domain. For example, Table S3 of the Supplement shows the monthly LAI profiles used for each PFT within the default CLM configuration. These profiles clearly show Northern Hemisphere growing cycles, which is problematic for SubSaharan Africa because it contains regions with bimodal tropical growing cycles and Southern Hemisphere growing cycles. Additionally, the visible spectrum dry soil albedo for the sandiest soils in the default CLM treatment is 0.24 , considerably less than the $0.25-0.45$ albedo from MODIS satellite estimates over most the Sahara (Wang et al., 2004).

\section{Updated CLM for Sub-Saharan Africa (CLM-AF)}

To address these limitations with CLM-D, and deficiencies of other LSMs described in the results section, the WRFCLM LSM has been modified to include PFT distributions that are more representative of the Sub-Saharan Africa domain, regionally varying monthly profiles for LAI and stem area index (SAI), minor improvements in vegetation optical properties (e.g., leaf reflectance), and scaled surface albedos for sandy soils to better match satellite estimates. Each of these modifications is described in detail below.

\subsection{CLM-AF PFT distributions}

Updated PFT distributions are derived from a global 3 arcmin PFT dataset for the year 2001 generated by the National Center for Atmospheric Research for the Model of Emission of Gases and Aerosols from Nature version 2.1 (https: //bai.ess.uci.edu/megan/data-and-code/megan21, last access: 20 May 2021). To determine the percentages of each PFT representative of the various MODIS land use categories in
Sub-Saharan Africa, the global PFT dataset is regridded to the $36 \mathrm{~km}$ WRF domain, and the average coverage of each PFT within each WRF-MODIS 2001 dominant land use category is calculated. Updated PFT distributions were generated for broadleaf evergreen or deciduous forests, mixed forests, closed and open shrublands, woody savannas or savannas, grasslands, and cropland or mosaic croplands (i.e., MODIS categories 2, 4-10,12, and 14). This limited subset of categories is used because the remaining MODIS categories did not cover a large enough area to be the dominant land use at $36 \mathrm{~km}$ resolution. Since CLM allows for up to four PFT patches, the top four most abundant PFTs within each MODIS land use category are scaled to represent $100 \%$ of the land use category, with an exception for some inconsistencies that occurred between the PFT and the evergreen broadleaf forest, savanna, and mosaic cropland MODIS categories (see Supplement ST1). The resulting updated PFT distribution for these CLM vegetated land use categories is shown in Table 2.

Most of the updated PFT distributions in Table 2 are consistent with the MODIS International Geosphere-Biosphere Programme (IGBP) category descriptions from Friedl et al. (2002) (Table S4, Supplement). However, there are two minor inconsistencies with the closed shrubland and grassland categories. The closed shrubland category contains slightly less than $60 \%$ shrubs and $8 \%$ deciduous tropical trees, indicating there is some sub-grid-scale overlap with nearby woody savannas or forests. The grasslands category contains $18 \%$ shrubs, which is higher than the $10 \%$ from the description in Table S4, indicating some overlap with sub-grid-scale shrublands. Overall, compared to the CLMD PFT distributions in Table S2, the updated values in CLM-AF have greater heterogeneity in plant types and contain more herbaceous cover. The largest deviations from the CLM-D distribution occur with shrublands and woody savanna. CLM-D prescribes all shrublands as broadleaf evergreen shrubs, while the global PFT dataset indicates that shrublands in Sub-Saharan Africa contain broadleaf deciduous temperate shrubs. Additionally, the woody savanna category PFT distribution in CLM-D is identical to closed shrubland. This is potentially a large source of error, as woody savanna should have forest cover between $30 \%$ and $60 \%$ (Table S4 in the Supplement). This error is removed in the CLM-AF PFT distribution with the woody savanna category containing $38 \%$ tree cover.

\subsection{CLM-AF LAI and SAI profiles}

Since the Sub-Saharan Africa domain covers a wide range of tropical and sub-tropical latitudes, a single domain-wide LAI and SAI monthly profile for each PFT is not appropriate. Here, geographically varying monthly LAI profiles are generated by using 17 distinct regions based on bioclimate characteristics used in LULCC modeling of SubSaharan Africa (Fig. 1 and Table 3). These bioclimate re- 
Table 2. Percentage of plant functional types assigned to MODIS land use categories in the updated CLM-AF.

\begin{tabular}{lrrrrrrrrrr}
\hline MODIS land use category & 2 & 4 & 5 & 6 & 7 & 8 & 9 & 10 & 12 & 14 \\
\hline Bare soil & - & 3 & - & 14 & 48 & - & - & 21 & 10 & - \\
Broadleaf evergreen tropical tree & 82 & - & 20 & - & - & 12 & - & - & - & - \\
Broadleaf evergreen temperate tree & 18 & - & 15 & - & - & - & - & - & - & - \\
Broadleaf deciduous tropical tree & - & 55 & - & 8 & - & 26 & 21 & - & - & 24 \\
Broadleaf deciduous temperate shrub & - & 18 & - & 57 & 31 & - & - & 18 & - & - \\
$C_{3}$ Non-arctic grass & - & - & 40 & - & 8 & 27 & 31 & 36 & 24 & 17 \\
$C_{4}$ grass & - & 24 & 25 & 21 & 13 & 35 & 48 & 25 & 15 & 33 \\
Corn & - & - & - & - & - & - & - & - & 51 & 26 \\
\hline
\end{tabular}

MODIS land use categories are numbered as follows: 2 : evergreen broadleaf forest; 4 : deciduous broadleaf forest; 5 : mixed forest; 6: closed shrublands; 7: open shrublands; 8: woody savanna; 9: savanna; 10: grasslands; 12 : croplands; 14: cropland and natural mosaic.

Table 3. Dominant MODIS-IGBP land use categories within African bioclimate regions at $36 \mathrm{~km}$ resolution.

\begin{tabular}{ll|ccccccccccc}
\hline \multicolumn{1}{c}{ Region } & & \multicolumn{10}{|c}{ MODIS-IGBP category } \\
\hline Name & Acronym & 2 & 4 & 5 & 6 & 7 & 8 & 9 & 10 & 12 & 14 \\
\hline North dry & ND & - & - & - & - & $\mathrm{Y}$ & - & - & $\mathrm{Y}$ & $\mathrm{Y}$ & $\mathrm{Y}$ \\
East dry & ED & - & $\mathrm{Y}$ & - & - & $\mathrm{Y}$ & - & - & $\mathrm{Y}$ & - & $\mathrm{Y}$ \\
Northeast semi-dry* & NESD & - & - & - & $\mathrm{Y}$ & $\mathrm{Y}$ & $\mathrm{Y}$ & $\mathrm{Y}$ & $\mathrm{Y}$ & $\mathrm{Y}$ & $\mathrm{Y}$ \\
West semi-dry & WSD & - & - & - & - & $\mathrm{Y}$ & - & $\mathrm{Y}$ & $\mathrm{Y}$ & $\mathrm{Y}$ & $\mathrm{Y}$ \\
East wet & EW & $\mathrm{Y}$ & - & - & - & - & $\mathrm{Y}$ & $\mathrm{Y}$ & $\mathrm{Y}$ & $\mathrm{Y}$ & $\mathrm{Y}$ \\
West moist & WM & - & - & - & - & - & $\mathrm{Y}$ & $\mathrm{Y}$ & - & $\mathrm{Y}$ & $\mathrm{Y}$ \\
West wet & $\mathrm{WW}$ & $\mathrm{Y}$ & - & - & - & - & $\mathrm{Y}$ & $\mathrm{Y}$ & $\mathrm{Y}$ & - & $\mathrm{Y}$ \\
Central wet* & $\mathrm{CW}$ & $\mathrm{Y}$ & - & - & - & $\mathrm{Y}$ & $\mathrm{Y}$ & $\mathrm{Y}$ & $\mathrm{Y}$ & - & $\mathrm{Y}$ \\
West wet Nigeria & $\mathrm{WWN}$ & $\mathrm{Y}$ & - & - & - & - & $\mathrm{Y}$ & $\mathrm{Y}$ & - & $\mathrm{Y}$ & $\mathrm{Y}$ \\
Central moist* & $\mathrm{CM}$ & $\mathrm{Y}$ & - & - & - & - & $\mathrm{Y}$ & $\mathrm{Y}$ & $\mathrm{Y}$ & $\mathrm{Y}$ & $\mathrm{Y}$ \\
Lake Victoria wet & LVW & $\mathrm{Y}$ & - & - & - & - & $\mathrm{Y}$ & $\mathrm{Y}$ & $\mathrm{Y}$ & $\mathrm{Y}$ & $\mathrm{Y}$ \\
East moist & EM & $\mathrm{Y}$ & - & $\mathrm{Y}$ & - & - & $\mathrm{Y}$ & $\mathrm{Y}$ & $\mathrm{Y}$ & - & $\mathrm{Y}$ \\
Southeast semi-dry & SESD & - & - & - & - & $\mathrm{Y}$ & $\mathrm{Y}$ & $\mathrm{Y}$ & - & - & - \\
Madagascar & $\mathrm{MAD}$ & $\mathrm{Y}$ & $\mathrm{Y}$ & - & - & $\mathrm{Y}$ & $\mathrm{Y}$ & $\mathrm{Y}$ & $\mathrm{Y}$ & - & $\mathrm{Y}$ \\
South dry & SD & - & - & - & - & $\mathrm{Y}$ & - & - & - & - & - \\
South semi-dry & SSD & $\mathrm{Y}$ & - & - & $\mathrm{Y}$ & $\mathrm{Y}$ & $\mathrm{Y}$ & $\mathrm{Y}$ & $\mathrm{Y}$ & $\mathrm{Y}$ & - \\
South moist & SM & $\mathrm{Y}$ & - & - & - & $\mathrm{Y}$ & $\mathrm{Y}$ & $\mathrm{Y}$ & $\mathrm{Y}$ & $\mathrm{Y}$ & $\mathrm{Y}$ \\
\hline
\end{tabular}

* Indicates bioclimate regions that are subdivided into a north, a south, or other sub-bioclimate region for better LAI geographical distributions.

gions are constructed for land use modeling purposes as discussed in Sect. 4.3 because landscape dynamics are known to be different between broad climatic zones, needing separate modeling parameterizations (Soares-Filho et al., 2006). These same bioclimate regions are ideal for parameterizing LAI and SAI profiles because they divide the region based on climate characteristics that impact vegetation. However, the central wet $(\mathrm{CW})$, central moist (CM), and northeast semidry (NESD) bioclimate regions used in the land use modeling span a large latitudinal range and are subdivided based on latitude to generate more meaningful LAI seasonal profiles (Supplement ST2).

The updated LAI profiles within each bioclimate region are derived from both the $36 \mathrm{~km}$ regridded global PFT dataset and the monthly LAI climatology data, provided by WPS, used in the Noah-Sat configuration. LAI profiles are calcu- lated only from a subset of grid cells within the WPS SubSaharan Africa LAI climatology, where the $36 \mathrm{~km}$ regridded PFT data indicates that a given PFT comprises $80 \%$ or more of the grid cell (PFT80). For the broadleaf evergreen tree PFTs, the median monthly LAI value of the PFT80 grid cells within each bioclimate or sub-bioclimate region is used as the monthly prescribed LAI value for that PFT. Median values are used in place of mean values for the broadleaf evergreen tree PFTs because several small LAI values near the edges of forested regions lead to unrealistically small LAI values for the Congo and other forests compared to the WPS LAI satellite-derived climatology. For the remaining PFTs, the mean monthly LAI value of the PFT80 grid cells within each bioclimate or sub-bioclimate region is used as the monthly prescribed LAI value for that PFT. The monthly LAI profiles for each PFT within each bioclimate and sub- 
bioclimate region are listed in Tables S5-S11 of the Supplement. If no grid cells within a bioclimate or sub-bioclimate region meet the PFT80 criteria for a required PFT, then a reduced threshold of $60 \%$ of the grid cell is utilized to calculate the monthly LAI profile for that PFT. If no grid cells meet the $60 \%$ criteria, the LAI profile for that PFT within the bioclimate or sub-bioclimate region is assumed to be the same as a nearby comparable bioclimate region. These comparable "alternative" bioclimate regions are listed in Table 4. The first nearby alternative bioclimate region used to generate LAI profiles for the missing PFTs is listed as "first region" in Table 4. If the first region does not have all the missing PFT LAI profiles, then these profiles are obtained from a second nearby bioclimate region ("second region"). Some additional adjustments were also required for the broadleaf evergreen tree PFTs to make these areas more consistent with the satellite-derived climatology (Supplement ST3).

SAI represents the area of stems and dead leaves. The values of SAI are poorly known, but SAI is generally parameterized to have a minimum in winter and maximum in autumn for each land cover type (Tian et al., 2004a). Since no readily available data on SAI exist, SAI within CLM-AF is based on relating decreases in LAI ( $\triangle \mathrm{LAI})$ from month to month to the SAI values in the CLM-D configuration. This is done by fitting a simple linear regression between $\triangle \mathrm{LAI}$ and the SAI value in CLM-D. If the LAI is not decreasing from the previous month then the SAI value is assumed to be the minimum value from CLM-D. These assumptions are consistent with the definition of SAI as dead leaves and litter will only increase when LAI is decreasing. However, it was not possible to generate linear regressions for evergreen trees and corn from CLM-D because the evergreen tree LAI profiles in CLM-D do not change from month to month and the corn SAI profile is equivalent to the corn LAI profile. These assumptions are not appropriate for Sub-Saharan Africa because of the longer tropical growing season and small seasonal fluctuations in evergreen tree LAI in the satellite climatology. Therefore, corn within CLM-AF is assumed to have the same $\mathrm{SAI}$ profile as $\mathrm{C}_{4}$ grass, and evergreen trees follow a similar equation to $\mathrm{C}_{4}$ grass with an intercept equivalent to the appropriate evergreen tree minimum SAI value of 0.5. A list of the SAI profile equations and minimum SAI values in the CLM-AF configuration for the updated PFTs are listed in Table 5.

\subsection{CLM-AF sandy soil albedo}

CLM-D sandy soil albedos and updated values for CLM-AF are listed in Table 6. CLM simulates surface albedo using a look-up table for different soil color classes with two different radiation streams that differentiate between saturated and dry soils. Albedo values in the sandy soils of the Sahara range from 0.25 to 0.45 (Wang et al., 2004), which is larger than the 0.24 dry sandy soil albedo in CLM-D. Accordingly, we increased the albedo values for sand and sand-loam com- bination soil types by 0.1 and 0.02 , respectively. This puts the sandy soil albedos inside the range expected for the Sahara, while not leading to excessively large albedos in the deserts of southern and eastern Africa.

\subsection{CLM-AF vegetation property adjustments}

In order to bring the albedo of vegetated areas into better agreement with the satellite climatology from WPS, several adjustments are made to leaf and vegetation optical properties in CLM-AF. In CLM-D, shrubs in SubSaharan Africa are erroneously classified as broadleaf evergreen shrubs rather than temperate deciduous shrubs. In order to maintain a lower albedo for these African shrubs, the leaf transmittance, leaf angle, and leaf reflectance properties of the deciduous temperate shrubs are adjusted to match those of broadleaf evergreen shrubs. Additionally, the near-infrared leaf reflectance of all broadleaf tree species is lowered from 0.45 to 0.35 in CLM-AF, which is in better agreement with near-infrared leaf reflectance measured by unmanned-aerial-vehicle-mounted hyperspectral imaging instruments over African forest canopies (Thomson et al., 2018).

\section{Experimental design}

This study consists of two experiments (Table 7). The first is a meteorological evaluation experiment to compare differences between the WRF LSM configurations and assess the impact of their prescribed surface parameters on meteorological model performance. The second is a LULCC experiment to determine if the errors and uncertainties of each LSM lead to differences in their climate responses to LULCC.

\subsection{Meteorological evaluation experiment}

The meteorological evaluation experiment consists of five simulations conducted for the year 2013, each using one of the five LSM configurations discussed above. The year 2013 is selected because it is a neutral year for the El Niño Southern Oscillation (ENSO) and thus should be representative of the mean state of Sub-Saharan Africa's ENSO climate variability. While a single-year comparison does not yield climate relevant statistics, it is sufficient to demonstrate differences in the meteorology between the five LSM configurations and the mechanisms responsible for these differences. This is because the prescribed surface parameters from the LSM do not vary between years and thus the impact from these parameters on the simulated meteorology will be similar (or at least the impact from each LSM will remain similar relative to the others) regardless of the model's overall meteorological state. The meteorological evaluation simulations are conducted with default greenhouse gas concentrations and MODIS 21 class land use data. These default settings 
Table 4. Regional interpolation of missing PFT data.

\begin{tabular}{lllll}
\hline Region & First region & PFTs & Second region & PFTs \\
\hline ND & WW & 4,5 & WSD & $6,10,11$ \\
ED & EW & 4,5 & NESD-N & $13,14,15$ \\
NESD-N & EW & 4,5 & - & - \\
NESD-S & EW & 4,5 & - & - \\
NESD-SH & EW & 4,5 & NESD-S & 6,15 \\
WSD & WW & 4,5 & - & - \\
EW & NESD-N & 10 & - & - \\
WM & WW & 4,5 & WSD & 10,13 \\
WW & WSD & 10 & - & - \\
CW-N & WSD & 10 & - & - \\
CW-S & SESD & 15 & - & - \\
CW-SA & CW-S & 6 & SESD & 15 \\
WWN & WW & 6 & WSD & 10 \\
CM-N & CW-N & $4,5,6$ & NESD-S & 10 \\
CM-S & CW-S & 6,10 & - & - \\
LVW & NESD-S & 6,10 & - & - \\
EM & CW-S & 6 & SESD & 10 \\
SESD & EM & 4,5 & - & - \\
MAD & SESD & 15 & - & - \\
SD & SSD & $4,5,6,14,15$ & - & - \\
SSD & - & - & - & - \\
SM & SSD & 14 & - & - \\
\hline
\end{tabular}

Table 5. Equations for calculating SAI for each PFT in CLM-AF.

\begin{tabular}{llr}
\hline PFT & SAI equation & SAI minimum \\
\hline Broadleaf evergreen trees & $\mathrm{SAI}=-\Delta \mathrm{LAI}+0.5$ & 0.5 \\
Broadleaf deciduous tropical trees & $\mathrm{SAI}=-1.0385(\Delta \mathrm{LAI})+0.2$ & 0.3 \\
Broadleaf deciduous shrubs & $\mathrm{SAI}=-0.8(\Delta \mathrm{LAI})+0.12$ & 0.1 \\
$\mathrm{C}_{3}$ Non-arctic grass & $\mathrm{SAI}=-0.9(\Delta \mathrm{LAI})+0.32$ & 0.1 \\
$\mathrm{C}_{4}$ Grass and corn & $\mathrm{SAI}=-\Delta \mathrm{LAI}+0.3$ & 0.3 \\
\hline
\end{tabular}

SAI: stem area index; $\Delta$ LAI: difference between the LAI of the current and previous month.

are chosen to illustrate the performance that can be expected from the publicly available WRF model.

\subsection{Land use and land cover change experiment}

The LULCC experiment simulates recent climate responses from LULCC since the year 2001 by comparing simulations with static LULC from 2001 with dynamic LULC representing 2010-2015. In both cases, meteorology is simulated for the 6-year period of 2010-2015. These two simulations differing in LULC are conducted for each LSM configuration using the Noah, Noah-MP, CLM-D, and CLM-AF LSMs. The first simulation for each LSM uses static LULC from MODIS representing the year 2001 for each simulated year (i.e., 2010-2015), hereafter referred to as LU01. The second uses dynamic LULC from the MODIS 21 class land use dataset that is processed by the Dinamica EGO land use modeling framework (Soares-Filho et al., 2002 - described in more detail below) for each simulated year in the 2010-2015 period, hereafter referred to as LUD. The 6-year average differences between the LU01 and LUD simulations delineate the climate response to LULCC. The time period 2010-2015 is selected because it is far enough away from the year 2001 to show significant impacts from LULCC and because it contains a full ENSO cycle. Noah-Sat is excluded because LAI and albedo parameters derived from satellite data could be impacted by climatological variability, and therefore do not only represent LULCC. The LULCC simulations also utilize global average greenhouse gas concentrations for each simulation year (2010-2015) from the National Oceanic and Atmospheric Administration's (NOAA) Earth System Research Laboratory (ESRL) Global Monitoring Division (Dlugokencky and Tans, 2018). In the LULCC experiment, each year is a discreet simulation with a 3-month spin-up in which the model LULC is updated at the start of each year. This 
Table 6. Sandy soil CLM albedo values.

\begin{tabular}{lllr|rr}
\hline \multirow{2}{*}{ Moisture } & Radiation band & \multicolumn{2}{c|}{ CLM-D } & \multicolumn{2}{c}{ CLM-AF } \\
\cline { 3 - 6 } & & Sand & Sand-loam & Sand & Sand-loam \\
\hline \multirow{2}{*}{ Saturated } & Visible & 0.12 & 0.11 & 0.22 & 0.13 \\
& Infrared & 0.24 & 0.22 & 0.34 & 0.24 \\
\hline \multirow{2}{*}{ Dry } & Visible & 0.24 & 0.22 & 0.34 & 0.24 \\
& Infrared & 0.48 & 0.44 & 0.58 & 0.46 \\
\hline
\end{tabular}

Table 7. Model experiments and simulations.

\begin{tabular}{llll}
\hline Experiment & Period & Land use & LSM \\
\hline Meteorological evaluation & 2013 & Default & Noah \\
& & & Noah-Sat \\
& & & Noah-MP \\
& & & CLM-D \\
& & & CLM-AF \\
\hline Land use land cover change & $2010-2015$ & MODIS 2001 (LU01) & Noah \\
& & & Noah-MP \\
& & & CLM-D \\
& & Dinamica EGO 2010-2015 (LUD) & CLM-AF \\
& & & Noah \\
& & & CLM-D \\
& & & CLM-AF \\
\hline
\end{tabular}

is necessary because the WRF modeling framework treats LULC as a static field.

There are several nontrivial differences between the WRF default LULC used in the evaluation experiments and the MODIS data used in the LU01 simulation (Fig. S1), even though the WRF default LULC is intended to represent 2001. Overall, the default WRF LULC data has more area classified as grassland, savanna, and forest, with fewer areas classified as cropland, woody savanna, and barren land compared to the LU01 dataset. Spatially, the areas classified as cropland in LU01 are primarily classified as the nearest natural LULC type in the default dataset. In central Africa, some areas classified as forests and savannas in the default LULC dataset have been assigned as woody savanna in LU01. In southern Africa, some areas assigned as grasslands in the default LULC dataset are classified as open shrubland, and in arid regions some areas classified as open shrubland in the default dataset are assigned as barren land in LU01.

\subsection{LULC data}

The LULC dataset for the LULCC experiment are created by means of prospective landscape modeling techniques, and while simulations contain some level of model error, this approach is used to reduce the impact of potential LULC misclassification errors and uncertainties in the MODIS prod- uct that could propagate into the WRF model leading to "noisy" and inconclusive climate signals. To the authors' knowledge, this is a novel practice as many LULCC studies in Africa do not simulate year to year changes (e.g., Otieno and Anyah, 2012) from the LULC datasets or use idealized LULC datasets (e.g., Abiodun et al., 2008; Wang et al., 2016). The use of a simulated LULC product is sufficient to support the goals of the LULCC experiment, which aims to determine if the climate signals from realistic LULCC simulated by the different LSMs make logical sense.

LULCC is simulated using the Dinamica EGO environmental modeling platform (Soares-Filho et al., 2002). Dinamica EGO is a modeling tool designed to construct spatiotemporal models involving multiple transitions and iterations, dynamic feedbacks, sub-region approaches, and several spatial algorithms for the analysis and simulation of a wide variety of dynamic LULCC phenomena. Dinamica EGO has been used for many applications (Soares-Filho et al., 2002; De Almeida et al., 2005; Soares-Filho et al., 2006; Merry et al., 2009; Nepstad et al., 2009; Soares-Filho et al., 2010; Silvestrini et al., 2011; Thapa and Murayama, 2011; Bowman et al., 2012; Ghilardi et al., 2016; Oliveira et al., 2019; Cheng et al., 2020).

For input to our LULCC simulations, we use the MODIS land cover type product (MCD12Q1) consisting of a suite of datasets that provides global land cover maps at $500 \mathrm{~m}$ spatial 
resolution and annual temporal coverage from 2001 to 2013 and includes six different land cover classification schemes (Friedl et al., 2010; Friedl and Sulla-Menashe, 2015). This product is generated using an ensemble of supervised classification algorithms that uses MODIS nadir BRDF-adjusted reflectance data as input (Schaaf et al., 2002). Specifically, we use the IGBP classification legend since the land cover data used by the WRF model (Skamarock and Klemp, 2008) is based on MODIS-IGBP classification scheme. The MODIS land cover product has a post-process overall accuracy of $75 \%$ (Friedl et al., 2010).

Using this approach, we detected spurious changes that toggle yearly between classes such as woody savannas, savannas, or grasslands. To reduce this temporal noise, we apply a cell-based temporal mode filter that replaces cell values with the most frequently occurring LULC class selected from a moving but non-overlapping 3-year window (or alternatively a 6-year window when no mode is found) and assigning "no data" to the entire 12-year time series if it is still inconclusive. This filter preserves long-lasting changes while drastically reducing short-term changes between LULC classes. There is no edge preservation because windows do not overlap in time, i.e., LULC classes can change for 2001 or 2012. Consequently, the year of a "true" LULCC can be shifted forwards or backwards by 1 year.

Prospective landscape models covering very large areas need to be regionalized, meaning that during the calibration period, explanatory variables and their spatial relationships with observed changes can be tuned separately to capture the heterogeneity of landscape dynamics. Regions do not represent "hard borders" in modeling results, as the amount of projected change and the probability of change occurrences are not boxed in within regions, but the proximate causes of observed change can be analyzed separately.

For Dinamica EGO, Africa is regionalized into 18 regions based on climatic zones, demographic factors, and anthropogenic activity (Fig. S2) consisting of three overlapping layers: (1) United Nations geographic regions for Africa: northern, eastern, southern, western and central (UNSD, 1999); (2) a bioclimate layer from the modified version of the Global Environmental Stratification (GEnS) dataset (Metzger et al., 2013); and (3) residential-sector emissions hotspots using DICE-Africa emissions (Marais and Wiedinmyer, 2016). The resulting 67 categories are generalized into the final 18 based on neighborhood. The process of generalization is done by comparing major change trends among regions, trying to avoid the presence of separate regions with similar LULCC dynamics as much as possible. Of these 18 regions, 17 are used in the WRF modeling and for the generation of LAI and SAI profiles as described in Sect. 3.2 because the north semi-dry region is outside the Sub-Saharan Africa domain.

LULCC rates by region are analyzed by means of transition probability matrices, in order to quantify the amount of change (in $\mathrm{km}^{2}$ ) for each LULCC transition during the calibration period (2001-2007). Matrices are annualized and used to simulate expected annual LULCC up to 2013 for validation purposes.

While transition matrices project the expected amount of LULCC into the future, they say nothing about where this change is likely to occur. For each meaningful transition, a map depicting the probability of that transition happening in the future is built by means of analyzing the spatial relationship between observed changes and a set of explanatory variables (Table S12, Fig. S3). Static and dynamic explanatory variables were related by means of conditional probabilities with the spatial occurrence of observed LULCC for a subset of meaningful transitions during the calibration period. All maps were resampled to $1 \mathrm{~km}^{2}$ resolution and projected to the Africa Albers equal area conic coordinate system. Annual transition matrices (how much change is expected at each year) are integrated with annual probability maps (also generated for each year) to produce simulated land cover maps.

To evaluate the accuracy of simulations within the present time, simulated annual maps outside the calibration period (2008-2013) are compared with the MODIS product for the same year, using a fuzzy-logic method (Hagen, 2003) (Fig. S4). This approach incorporates a moving window neighborhood context, since predicting the location of LULCC transition at a pixel level is virtually impossible. The comparison is done between simulated and observed cells undergoing a certain LULCC within the windows. To measure the spatial agreement between maps, we used window sizes ranging from one to nine cells (corresponding to spatial resolutions between $500 \times 500 \mathrm{~m}$ and $4500 \times 4500 \mathrm{~m}$ ). For most transitions and regions, simulations correctly predict change within $4500 \times 4500 \mathrm{~m}$ windows $50 \%$ and $75 \%$ of cases, which is among the range of reported results in other prospective modeling studies (e.g., Soares-Filho et al., 2006, 2010; Thapa and Murayama, 2011; Carlson et al., 2012; Yi et al., 2012).

\subsection{Model evaluation datasets and protocol}

A list of data used to evaluate WRF's meteorological performance is shown in Table 8, and the WRF model variables evaluated against these datasets are listed in Table 9. Surface meteorological and climate quantities are validated against both hourly surface observations from the National Centers for Environmental Information Integrated Surface Dataset (NDEI-ISD) and monthly average gridded estimates from the University of East Anglia's Climate Research Unit version 4.02 (CRU TS4.02) dataset (Harris et al., 2014). Precipitation (PRE) is evaluated against CRU TS4.02, monthly average Global Precipitation Climatology Project (GPCP) (Adler et al., 2003) estimates, and $3 \mathrm{~h}$ average Tropical Rainfall Measurement Mission (TRMM) estimates. Cloud fraction (CF) and precipitable water vapor (PWV) are compared against estimates from the MODIS Terra Aerosol Cloud Water Vapor Ozone level-three product (MOD08_M3). Additionally, radiation balance variables are compared against 
Table 8. Datasets for meteorological evaluation.

\begin{tabular}{|c|c|c|c|}
\hline Datasets & $\begin{array}{l}\text { Temporal } \\
\text { resolution }\end{array}$ & $\begin{array}{l}\text { Spatial } \\
\text { resolution }\end{array}$ & Website \\
\hline CRU TS4.02 & Monthly & $0.5^{\circ} \times 0.5^{\circ}$ & $\begin{array}{l}\text { https://crudata.uea.ac.uk/cru/data/hrg/cru_ts_4.02/ (last access: } 13 \text { November } \\
\text { 2020) }\end{array}$ \\
\hline NCEI-ISD ${ }^{\mathrm{b}}$ & Hourly & $\mathrm{n} / \mathrm{a}$ & https://www.ncei.noaa.gov/data/global-hourly (last access: 26 November 2018) \\
\hline CERES-EBAF $^{\mathrm{c}}$ & Monthly & $1^{\circ} \times 1^{\circ}$ & https://ceres.larc.nasa.gov/ (last access: 16 October 2018) \\
\hline $\mathrm{GPCP}^{\mathrm{d}}$ & Monthly & $2.5^{\circ} \times 2.5^{\circ}$ & $\begin{array}{l}\text { http://www.esrl.noaa.gov/psd/data/gridded/data.gpcp.html (last access: } 15 \text { Oc- } \\
\text { tober 2018) }\end{array}$ \\
\hline $\mathrm{TRMM}^{\mathrm{e}}$ & $3 \mathrm{~h}$ & $0.25^{\circ} \times 0.25^{\circ}$ & $\begin{array}{l}\text { https://pmm.nasa.gov/data-access/downloads/trmm (last access: } 27 \text { November } \\
\text { 2018) }\end{array}$ \\
\hline MOD08_M3 ${ }^{\mathrm{f}}$ & Monthly & $1^{\circ} \times 1^{\circ}$ & $\begin{array}{l}\text { https://modaps.modaps.eosdis.nasa.gov/services/about/products/c61/MOD08_ } \\
\text { M3.html (last access: } 2 \text { October 2020) }\end{array}$ \\
\hline
\end{tabular}

\footnotetext{
${ }^{a}$ University of East Anglia, Climate Research Gridded Climate Data version 4.02. ${ }^{\mathrm{b}}$ National Centers for Environmental Information - Integrated Surface Data. ${ }^{\mathrm{c}}$ Clouds and Earth's Radiant Energy System - Energy Balanced and Filled. ${ }^{\mathrm{d}}$ Global Precipitation Climatology Project. ${ }^{\mathrm{e}}$ Tropical Rainfall Measuring Mission. ${ }^{\mathrm{f}}$ MODIS/Terra Aerosol Cloud Water Vapor Ozone Monthly L3 Global 1Deg CMG. n/a: not applicable
}

Table 9. Evaluated variables and evaluation datasets.

\begin{tabular}{lll}
\hline Variable & Acronym & Evaluation dataset \\
\hline 2 m temperature & T2 & CRU TS4.02 and NCEI-ISD \\
Daily maximum temperature & T2MAX & CRU TS4.02 \\
Daily minimum temperature & T2MIN & CRU TS4.02 \\
Diurnal temperature range & DTR & CRU TS4.02 \\
2 m vapor pressure & E2 & CRU TS4.02 \\
2 m dew point temperature & Td 2 & NCEI-ISD \\
Precipitable water vapor & PWV & MOD08_M3 \\
Cloud fraction & CF & CRU TS4.02 and MOD08_M3 \\
Precipitation & PRE & CRU TS4.02, GPCP, and TRMM \\
10m wind speed & WSP10 & NCEI-ISD \\
Downwelling shortwave radiation (surface) & SWDOWN & CERES-EBAF \\
Downwelling longwave radiation (surface) & GLW & CERES-EBAF \\
Upwelling Shortwave Radiation (TOA*) & SWUPT & CERES-EBAF \\
Upwelling shortwave radiation (surface) & USRS & CERES-EBAF \\
Upwelling longwave radiation (TOA*) & OLR & CERES-EBAF \\
Shortwave cloud forcing & SWCF & CERES-EBAF \\
Longwave cloud forcing & LWCF & CERES-EBAF \\
\hline
\end{tabular}

* Top of the atmosphere.

satellite estimates from the Clouds and Earth's Radiant Energy System - Energy Balanced and Filled (CERES-EBAF) surface and top of the atmosphere datasets edition 4.0.

To compare WRF to the gridded datasets, the WRF output is averaged to the appropriate temporal resolution and regridded to the native horizontal resolution of the gridded products to calculate performance statistics. Comparisons against NCEI-ISD are made for each hour by pairing the monitoring station values to the value of the WRF $36 \mathrm{~km}$ grid cell containing the monitoring station. All comparisons with MOD08_M3 are done by averaging the WRF data during the daytime MODIS Terra overpass times of Sub-Saharan Africa (i.e., 06:00-12:00 UTC). Model performance is determined by calculating the normalized mean bias (NMB) and normalized mean error (NME). Statistical quantities are calculated for the domain as a whole and each bioclimate region to show regional variability in model performance. Additionally, spatial patterns for the simulations and observations are shown.

\section{Results - surface parameters}

It is important to illustrate the different surface properties from each LSM within WRF using the same LULC because these surface properties differences will drive simulated changes in the meteorology. Figures 2-4 depict the surface properties for each of the five LSM configurations from the 2013 evaluation simulations. Since the albedo and LAI of 

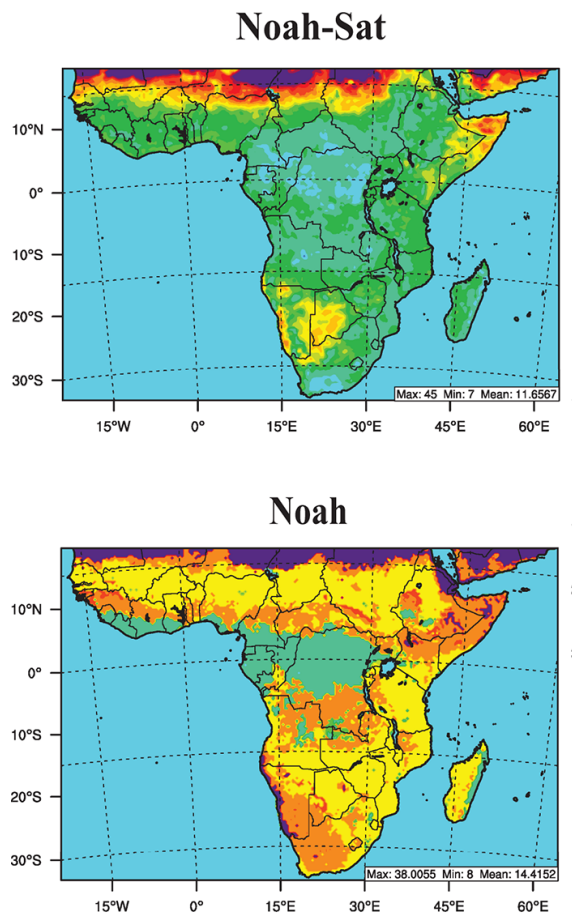
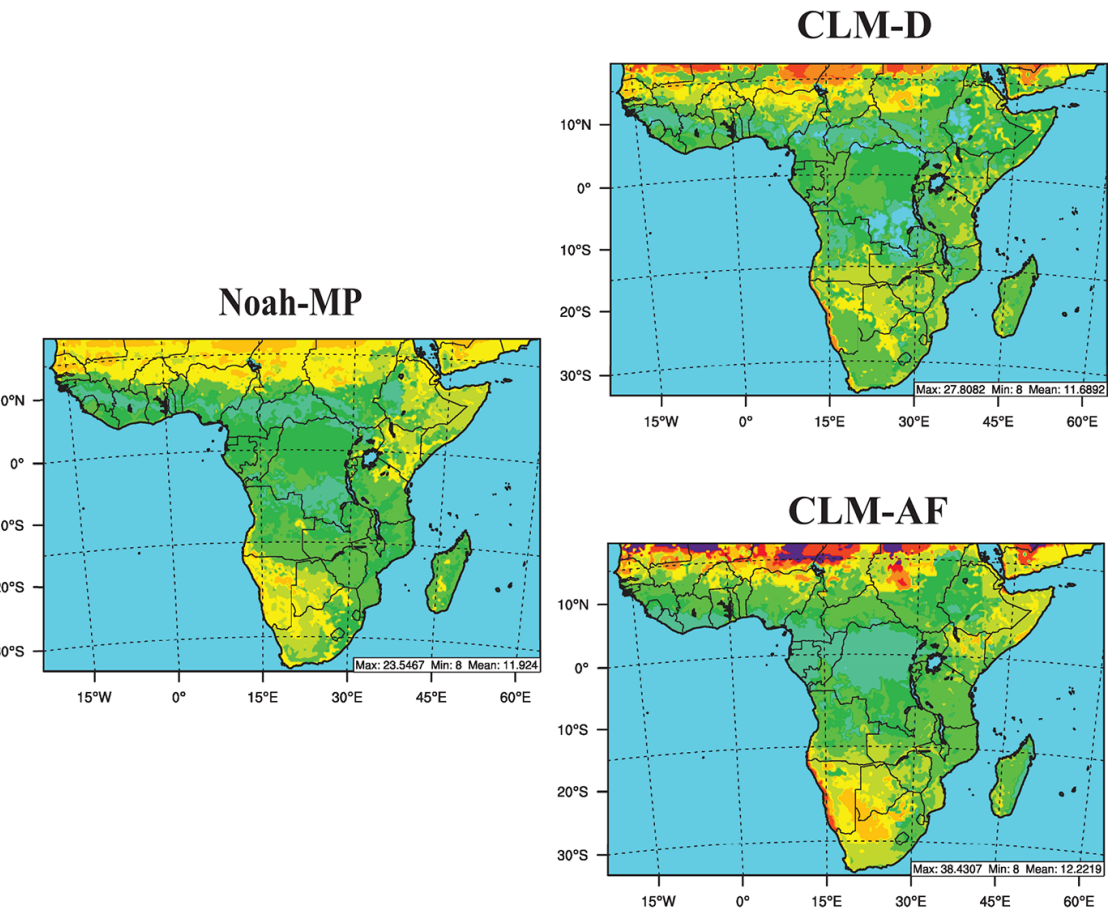

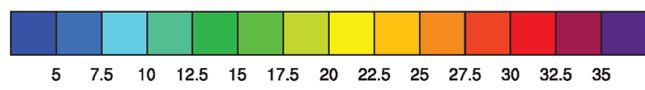

Figure 2. Comparison of annual average albedo (\%) between LSM configurations. Since Noah-Sat is based on satellite observations, it can be treated as observations.

Noah-Sat are generated from satellite estimates, these values can be considered similar to observations.

In general, all of the LSM configurations that prescribe albedo overpredict surface albedo in vegetated areas. However, the Noah LSM severely overpredicts surface albedo throughout the entirety of the domain, with albedo values ranging from $\sim 20 \%$ to $28 \%$ for regions containing woody savanna, savanna, and shrubland (Fig. 2), compared to $10 \%$ to $20 \%$ over the same areas in Noah-Sat. This is because Noah's prescribed albedo values for many of the MODISIGBP categories are significantly larger than those derived from satellites (Table S13 in the Supplement). The annual average surface albedos prescribed by Noah-MP and CLM$\mathrm{D}$ are similar in magnitude and spatial pattern, with overpredicted albedo in vegetated areas and underpredicted albedo in arid regions. However, Noah-MP underpredicts surface albedo in the Sahara to a greater extent due to the loam soil simplification (Sect. 2.2.2). The Noah, Noah-MP, and CLMD LSM configurations all contain errors where woody savanna and closed shrubland are treated as either identical or similar. In the Noah LSM, this leads erroneously to the woody savanna regions having greater surface albedos than nearby savanna regions. In Noah-MP and CLM-D, this leads to woody savannas erroneously having lower albedos than nearby broadleaf evergreen forests because shrubs are assumed to have a lower leaf reflectance than broadleaf trees.
In general, CLM-AF is the closest match to the satellite spatial pattern, despite differences in magnitude. The prescribed albedo values in CLM-AF improve the representation of surface albedo in the arid regions of northern and eastern Africa, but the scaled values lead to overpredictions in southern Africa. Vegetated regions also contain higher albedo values than the satellite estimates. These errors suggest that better representations of soil color and leaf reflectance are needed in WRF-CLM.

In general, all of the LSM configurations that prescribe LAI overpredict the LAI of arid regions compared to satellite estimates (Fig. 3). Due to the lack of geographically varying LAI in CLM-D, the seasonality of LAI in Sub-Saharan Africa in this configuration is incorrect with elevated LAI values throughout the entire domain for June, July, and August (JJA) and minimum LAI values throughout the domain in December, January, and February (DJF). Additionally, woody savanna LAI in CLM-D is significantly underpredicted because it has the same LAI profile as closed shrubland.

Unlike CLM-D, the Noah and Noah-MP configurations account for differences in seasonality in the Northern Hemisphere and Southern Hemisphere by shifting the Northern Hemisphere LAI profiles by 6 months for the Southern Hemisphere. This approach leads to differentiated Northern Hemisphere and Southern Hemisphere LAI values in Noah 

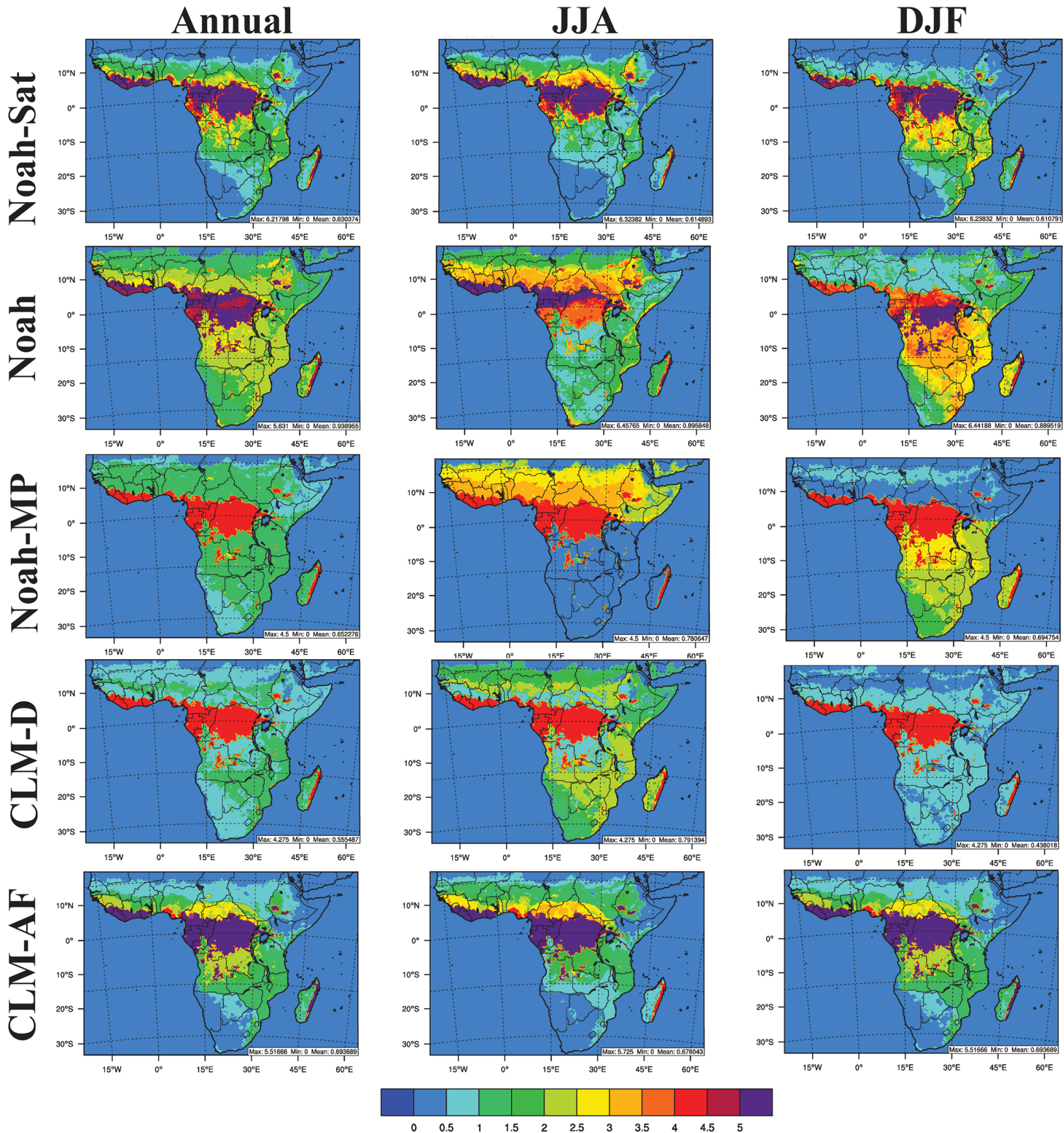

Figure 3. Comparison of annual, summer (JJA), and winter (DJF) average LAI $\left(\mathrm{m}^{2} \mathrm{~m}^{-2}\right)$ between LSM configurations. Since Noah-Sat is based on satellite observations, it can be treated as observations.

and Noah-MP (Fig. 3); however, distinct discontinuities occur in LAI at the Equator. In Noah-MP this LAI discontinuity only impacts East Africa due to the presence of broadleaf evergreen forest with a time-invariant LAI profile (category 2 in Table S14) in central Africa. This issue is more apparent in the Noah LSM as the LAI discontinuity occurs in both eastern and central Africa, since all the LULC categories in this region have time-variable maximum and minimum LAI values (Table S15 of Supplement). Additionally, the LAI profiles in Noah-MP (Table S14) have a stronger seasonality than the Noah values due to many LULC categories having much lower minimum values of $\sim 0.0-0.5$ during the winter months. This leads to an overall underpredicted LAI during the winter periods in both hemispheres and overpredicted 

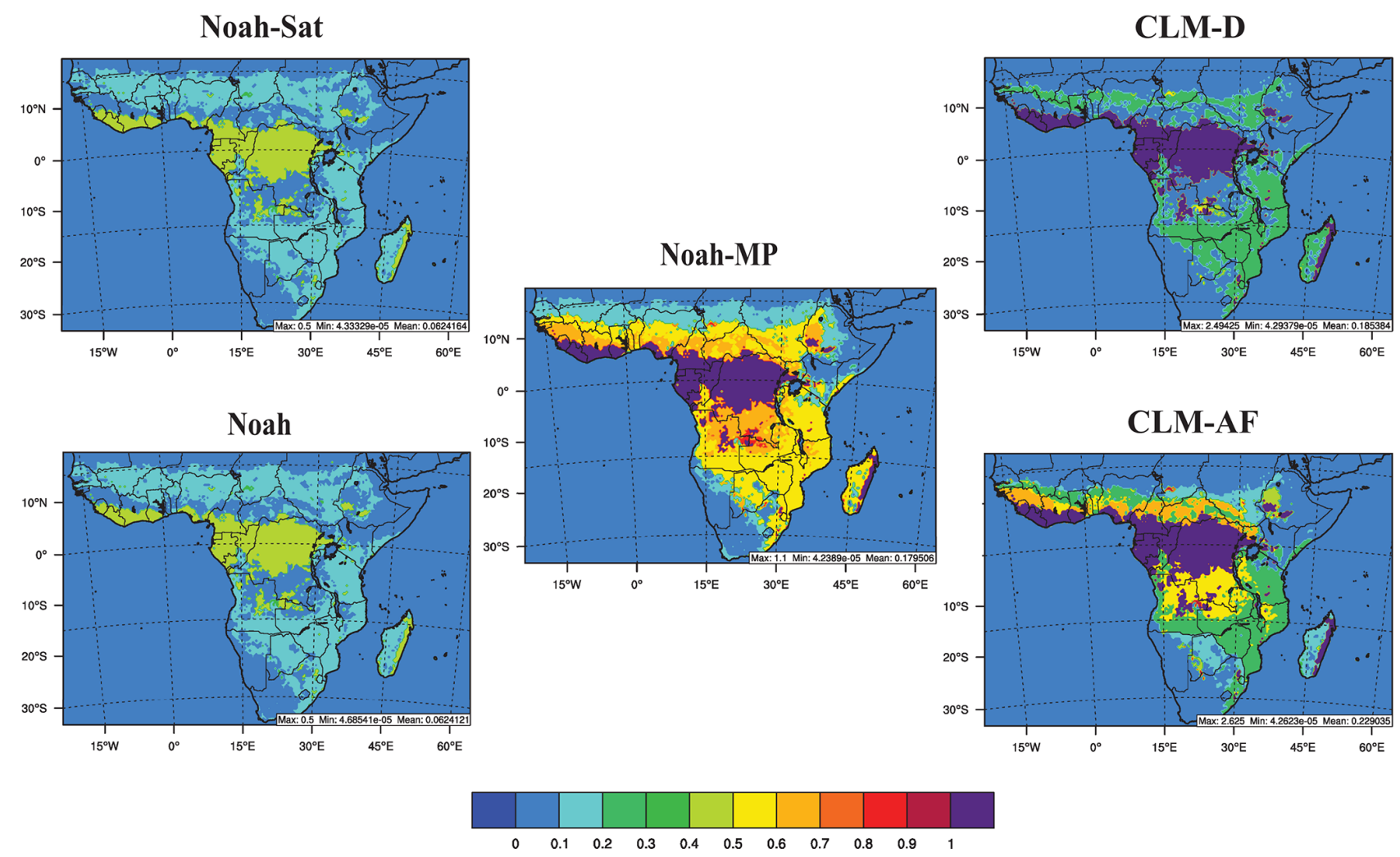

Figure 4. Comparison of annual average surface roughness length $(\mathrm{m})$ between LSM configurations.

LAI during the summer periods. The net effect of this error is an overall underprediction in the annual average LAI of tropical heavily vegetated regions and slightly overpredicted annual LAI in sub-tropical arid regions. The generally higher minimum and maximum LAI values in the Noah LSM lead to generally accurate annual average LAI values in tropical regions but significantly overpredicted annual LAI values in sub-tropical arid regions. The errors in the LAI profiles of Noah and Noah-MP likely occur because they have been developed mainly for application in the Northern Hemisphere midlatitudes.

CLM-AF generates annual and seasonal average LAI spatial patterns that largely mimic the satellite estimates (NoahSat). The use of LAI profiles prescribed in smaller regions has eliminated any large and obvious discontinuities and better represents the latitudinal variability and seasonality in LAI compared to the other LSM configurations. CLM-AF slightly underpredicts LAI values in the southeastern portion of the domain and slightly overpredicts LAI near the Sahara. These errors likely result from the lack of spatial heterogeneity that can be expected from a look-up table methodology.

An observational RL dataset is not available for comparison with model estimated RL. However, a comparison of the modeled RL (Fig. 4) reveals several critical issues with the default representations. Despite having accurate LAI and surface albedo from satellite estimates, the Noah-Sat configura- tion uses the same methodology as Noah to prescribe RL and therefore both LSMs possess the same limitations. The values of RL in Noah and Noah-Sat are very low in comparison to other LSMs, with a maximum value over forested regions of $0.5 \mathrm{~m}$. This is inconsistent with the MODIS-IGBP evergreen broadleaf forest definition of canopies larger than $2 \mathrm{~m}$ (Table S4), indicating that both of these configurations likely underestimate RL. Additionally, the spatial patterns in Noah, Noah-Sat, and CLM-D are all incorrect due to prescribing woody savanna regions as having shrubland RL values. The Noah-MP and CLM-AF LSMs have the most realistic spatial patterns and magnitudes of RL. The key differences are higher RL values for herbaceous land cover types in NoahMP and larger maximum RL values over forested regions in CLM-AF.

For both latent (LH) and sensible (HFX) heat fluxes (Figs. 5 and 6), all LSMs produce similar annual average spatial distributions. LH are more similar amongst LSMs (Fig. 5), with the key difference being larger LH $(\sim 10$ $20 \mathrm{~W} \mathrm{~m}^{-2}$ ) in the most heavily vegetated portions of the domain for the CLM-D and CLM-AF configurations. The similar LH for CLM-D and CLM-AF suggests a mechanistic difference that may be related to the vegetation canopy approximation in CLM that does not account for gaps within the canopy or between vegetation crowns. However, the values are the largest for CLM-AF in regions containing savanna, 

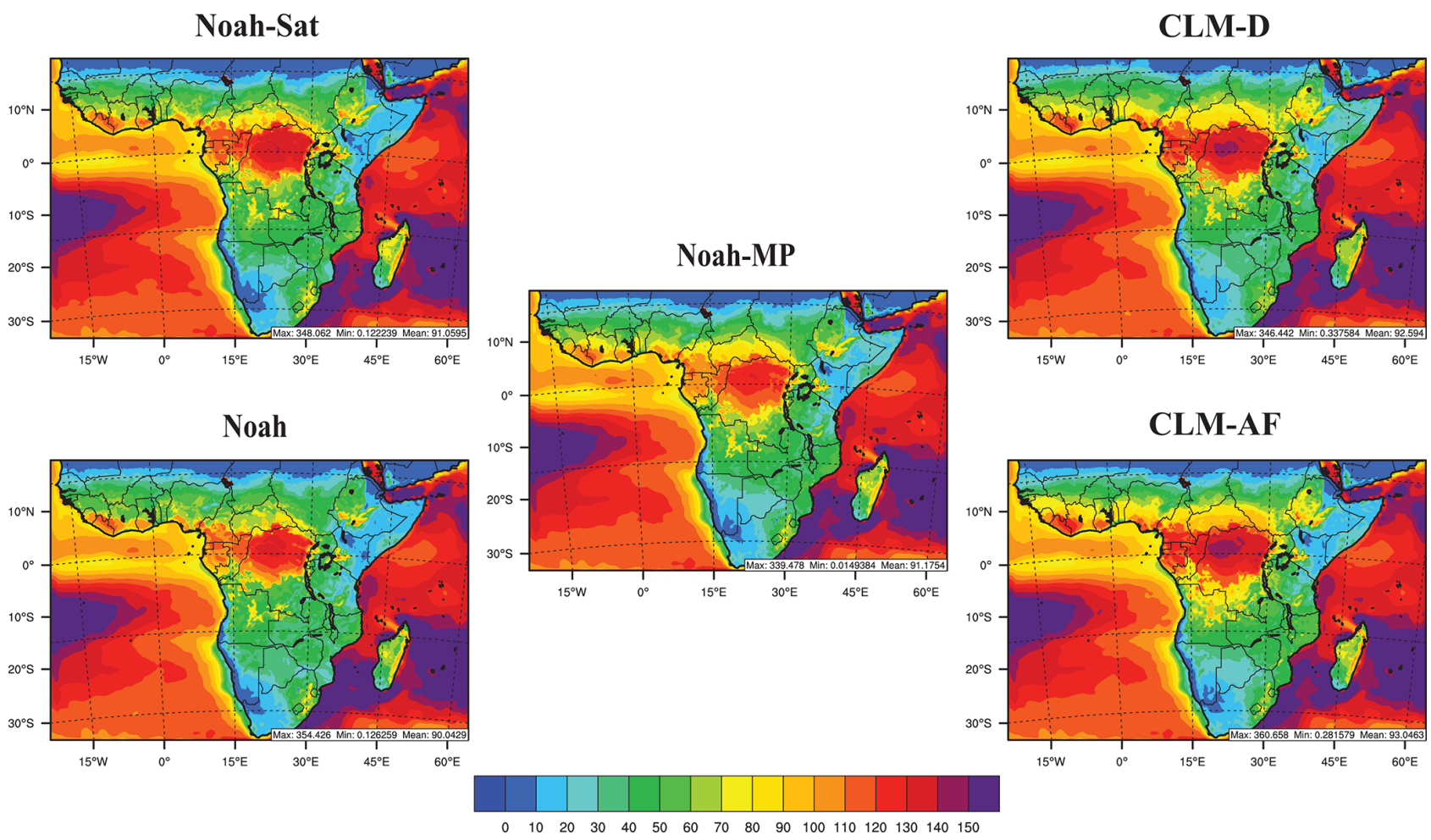

Figure 5. Comparison of annual average latent heat flux $\left(\mathrm{W} \mathrm{m}^{-2}\right)$ between LSM configurations.

likely due to the larger values of LAI in these regions during the drier seasons (Fig. 3).

For HFX (Fig. 6), the Noah-Sat LSM produces the largest fluxes, especially in the semi-dry regions of eastern and southern Africa. This is likely a combination of Noah-Sat having the lowest albedo in vegetated regions leading to more surface energy absorption and Noah-Sat having consistently low LAI values in these regions throughout the year compared to other LSMs (Figs. 2 and 3). Both CLM-D and CLMAF have lower HFX compared to the other LSMs in vegetated areas, again likely due to the vegetation canopy assumptions. However, CLM-D has higher HFX in southern Africa, comparable to those of Noah and Noah-MP. This is likely the result of Noah, Noah-MP, and CLM-D having much larger than realistic fluctuations in LAI between the wetter and drier seasons in this region (Fig. 3).

\section{Results - 2013 meteorological evaluation}

The primary meteorological variable impacted by surface albedo is the upwelling surface shortwave radiation flux at the Earth's surface (USRS). Annual average spatial plots of USRS compared with CERES-EBAF estimates are shown in Fig. 7, with seasonal average spatial plots shown in Fig. S5 of the Supplement. Additionally, annual average difference plots with CERES-EBAF for each LSM are shown in Fig. S6. All plots illustrate that the Noah-Sat configuration, with satellite albedo estimates, has the best agreement between simulated USRS and CERES-EBAF. The performance of the remaining LSMs follows their agreement with the satellite albedo climatology (Fig. 2), where CLM-AF has the best performance and Noah the worst. Model performance is further quantified using soccer plots (Fig. 8) of domainwide and African bioclimate region NMB and NME statistics for simulated USRS and $2 \mathrm{~m}$ temperature (T2) compared to CERES-EBAF and CRU/NCEI-ISD observations. These statistics confirm that Noah-Sat has the best overall USRS performance and that Noah significantly overpredicts USRS in nearly all regions with overpredicted surface albedo. The statistical performance of CLM-D, Noah-MP, and CLM-AF are similar in many African bio-climate regions, with CLMAF generally having the best overall agreement. In particular, CLM-AF simulates USRS more accurately in the arid ND and ED regions than both Noah-MP and CLM-D, which indicates that the increased sandy soil albedos in CLM-AF improve model performance. Additional radiative budget variables are evaluated against CERES-EBAF estimates in the Supplement (Figs. S7-S9). We find that most other radiative parameters have minimal differences between LSMs, with most errors resulting from underestimated cloud radiative forcing consistent with other WRF experiments in Africa (e.g., Diaz et al., 2015). The underestimated cloud radiative forcing seems to indicate the model is not generating clouds 

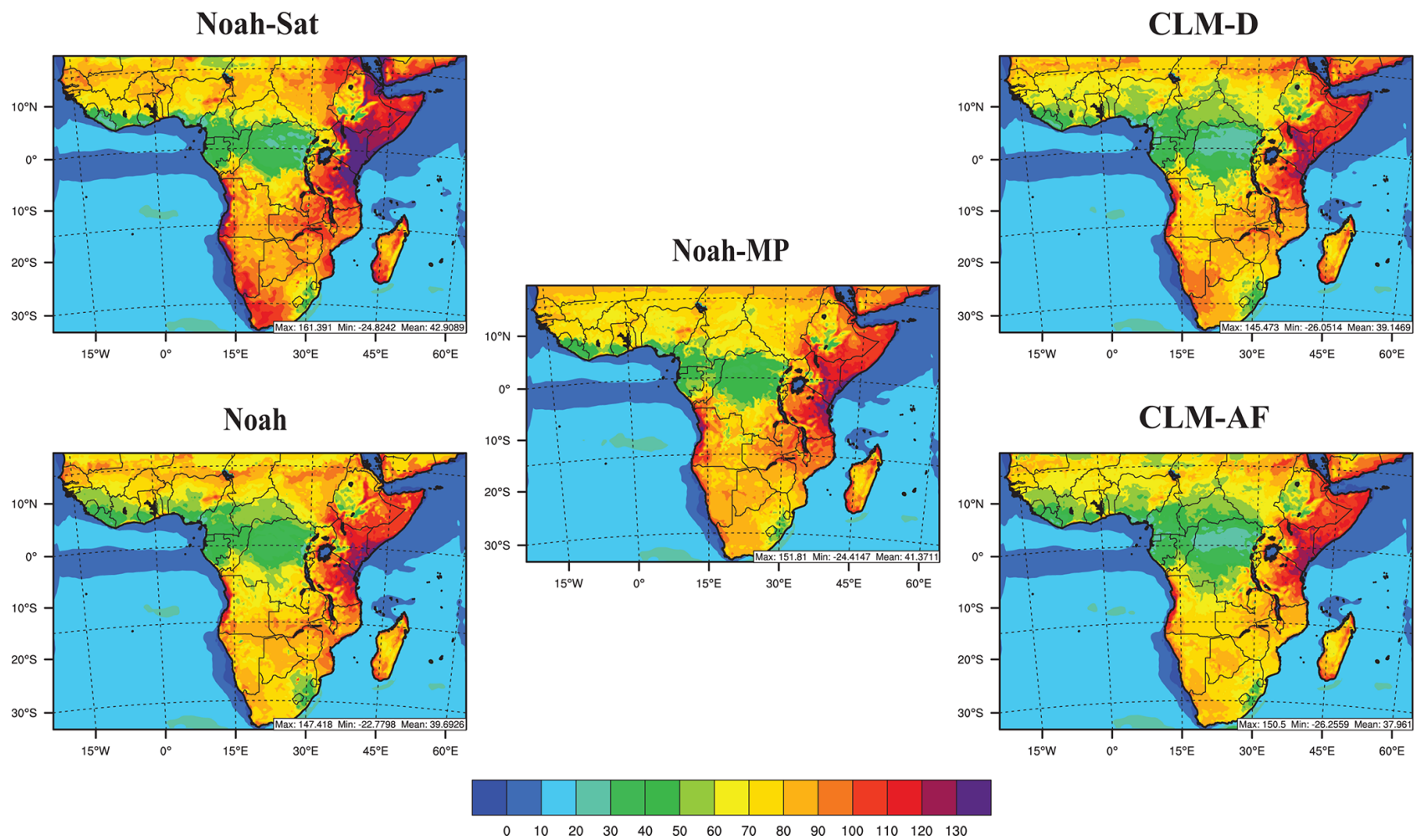

Figure 6. Comparison of annual average sensible heat flux $\left(\mathrm{W} \mathrm{m}^{-2}\right)$ between LSM configurations.

of sufficient optical thickness, since cloud fractions are overestimated compared to satellite estimates (Figs. 10, S15).

To understand the impact of surface parameters on near surface temperatures, the spatial plots of annual average $\mathrm{T} 2$ compared with CRU estimates are shown in Fig. 9, with seasonal spatial plots shown in Fig. S10 of the Supplement. Annual average differences between CRU and the LSMs are also shown in Fig. S11. Interestingly, despite clear deficiencies in surface parameters and USRS in many of the LSMs, all LSMs reasonably capture the spatial distribution and magnitude of annual (Fig. 9) and seasonal (Fig. S10) $\mathrm{T} 2$ as compared to CRU estimates. The only clear impact of surface albedo inaccuracy on annual average T2 is the relatively stronger cold bias in the Noah LSM (Figs. 9, S11). A closer inspection of T2 within Fig. 8 for the CRU dataset indicates that Noah-Sat, Noah, and Noah-MP all contain a domain-wide cold bias in annual average T2, while CLM-D and CLM-AF have minimal domain-wide T2 biases due to offsetting warm and cold biases in various regions. Several prior studies illustrate similar simulated T2 biases for African regions using WRF (e.g., Kerandi et al., 2017; Li et al., 2015). The evaluation differences above indicate that the mean $\mathrm{T} 2$ biases and errors likely result from differences in the way radiative and surface energy fluxes are parameterized in the LSMs, since the patterns in T2 predictions do not follow differences in surface parameters and incoming solar radiation is roughly equivalent for all
LSMs. This is further illustrated by the evaluation of daily maximum temperature (T2MAX) and daily minimum temperature (T2MIN) (Fig. S12). T2MAX is generally similar amongst all LSMs, except for Noah which contains a cold bias from the albedo overpredictions. The cold bias in Noah propagates to T2MIN, likely due to thermal inertia from underestimated daytime heating. Both Noah-Sat and Noah-MP have various offsetting cold and warm T2MIN biases in the African bioclimate regions, but CLM-D and CLM-AF both distinctly overpredict T2MIN. The overprediction of T2MIN in CLM-D and CLM-AF likely arises from the larger LH (Fig. 5) and upward surface longwave fluxes (not shown) predicted by these LSMs, which may be related to the vegetation canopy approximation in CLM, as previously discussed. These T2MIN overpredictions for CLM-D and CLM-AF also account for the lack of annual average cold bias in these simulations. Additionally, the underpredicted T2MAX in the Noah LSM and overpredicted T2MIN in CLM-D and CLMAF result in underpredicted diurnal temperature range (DTR) for these three LSMs.

The WRF comparison with the hourly NCEI-ISD dataset confirms the presence of a cold bias for the Noah LSM and provides more insight into regional model performance. Across all the LSMs, the wettest regions (e.g., MAD, WW, WWN, CW, LVW, EW) contain the strongest cold biases, while the semi-arid regions (e.g., SESD, WSD, NESD, SSD) contain the strongest warm biases. This would appear to in- 

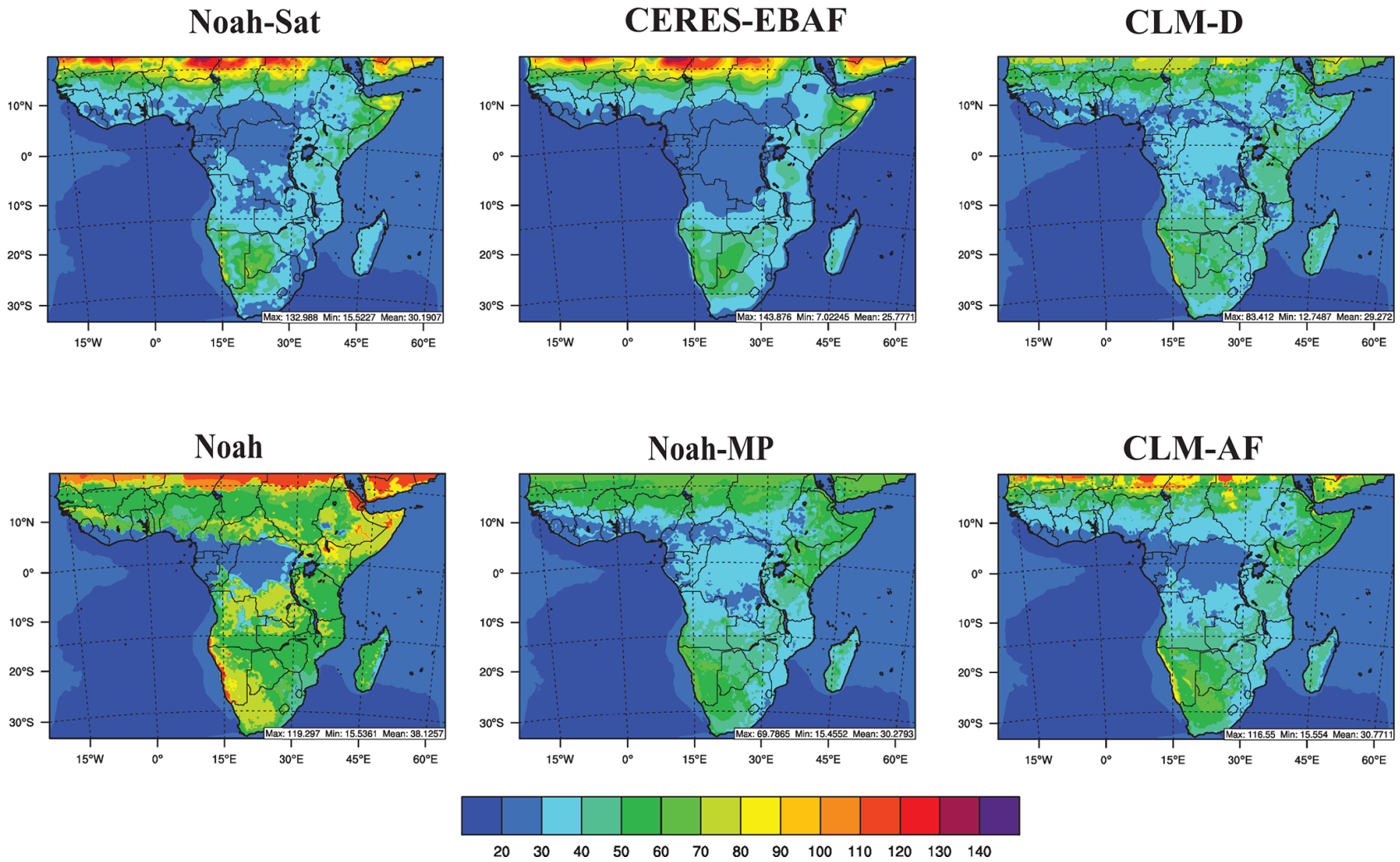

Figure 7. Year 2013 annual average upwelling shortwave radiation at the Earth's surface $\left(\mathrm{W} \mathrm{m}^{-2}\right)$ for CERES-EBAF estimates and WRF simulations.

dicate that hourly temperature biases are modulated by inaccuracies in cloud radiative forcing or evaporative cooling.

The evaluation of the moisture variables PWV, CF, and PRE against MODIS and TRMM estimates (Fig. 10) and the spatial comparison of WRF PRE to observations (Fig. 11) show a reduced impact from LSM differences compared to temperature variables. Most regions have reasonable agreement in moisture variables with observations and satellite estimates, with a few regions experiencing poor agreement (Fig. 10). All LSM simulations overpredict PWV and CF, while underpredicting PRE. This indicates a possible underrepresentation of moisture recycling in this WRF configuration, whereby insufficient moisture convergence or insufficient activation of the cumulus parameterization fails to trigger precipitation, leading to excess water vapor that forms cloud cover. These findings are consistent with underpredictions in precipitation from the modified Tiedtke cumulus parametrization found by Igri et al. (2018), indicating that this cumulus scheme may be less efficient at removing moisture from the atmosphere. The evaluation of $2 \mathrm{~m}$ dew point temperature (Td2) and $2 \mathrm{~m}$ vapor pressure (E2) against NCEI-ISD and CRU (Supplement Figs. S14 and S15) provide further evidence to support the possibility of insufficient moisture recycling as surface humidity is underpredicted, likely as a result of underpredicted PRE.
For a more detailed look at PRE, annual average spatial plots of PRE compared with CRU, GPCP, and TRMM estimates are shown in Fig. 11. Additionally, seasonal spatial plots of PRE compared with TRMM and annual average differences between TRMM and the LSMs and shown in Figs. S16 and S17, respectively. All LSM simulations reasonably capture the annual (Fig. 11) and seasonal (Fig. S16) spatial patterns and magnitude of PRE. Across all LSMs, PRE is better simulated in the wet regions of western and central Africa. The greatest underpredictions occur in arid regions (ND, ED, SD, NESD, and WSD) and portions of eastern Africa (EM, CM, and LVW), while regions in southern Africa (SSD and SM) and EW typically experience the strongest overprediction across the LSMs (Figs. 10, S13, S17). Similar regional model biases have been reported in other studies (Alaka and Maloney, 2017; Argent et al., 2015; Cretat et al., 2012; Ratnam et al., 2018), indicating that our results are comparable to the large body of work utilizing WRF to study African precipitation. More details regarding moisture variable evaluation can be found in the Supplement ST4.

Lastly, comparisons of $10 \mathrm{~m}$ wind speed (WSP10) to NCEI-ISD observations (Fig. S14 in the Supplement) show a few key differences in WSP10 performance between LSMs. Noah and Noah-Sat have nearly identical overpredictions in 

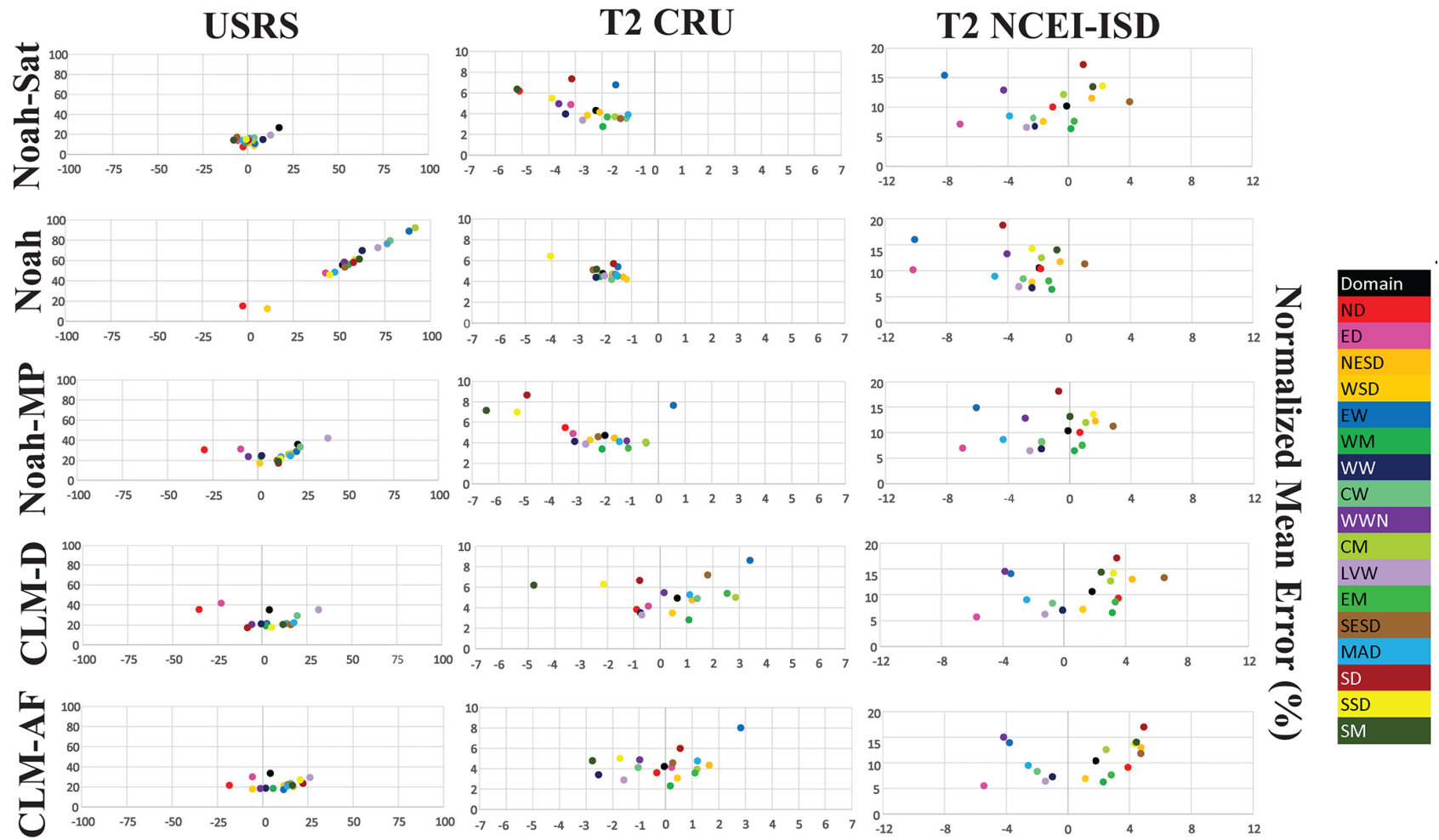

Normalized Mean Bias (\%)

Figure 8. Normalized mean error and mean bias statistics of USRS and T2 relative to observations, CERES-EBAF USRS estimates, and CRU/NCEI T2.

the magnitude of WSP10, associated with an underestimation of RL. CLM-D also underpredicts the magnitude of WSP10, associated with the underrepresentation of RL in woody savannas and the inaccurate seasonal profile of RL. Both Noah-MP and CLM-AF have offsetting overpredictions and underpredictions in various regions, but both LSMs underpredict WSP10 in equatorial forested areas, moderately underpredict or overpredict WSP10 in most moist vegetated regions, and largely overpredict WSP10 in more arid regions. The LSM regional model performance distribution may indicate that RL values in the forested regions are too large, and the RL values in more semi-arid regions are too small in the Noah-MP and CLM-AF configurations.

Overall, the meteorological evaluation experiments reveal little impact from inaccurate surface parameters on most meteorological parameters. The lack of poor meteorological performance may indicate that errors in surface parameters have minimal impacts on African meteorology for certain applications. However, these errors can impact the trajectory of LULCC-induced climate signals as demonstrated in Sect. 7.

\section{Results - impact of LULCC on regional climate using different LSMs}

LULCC, as represented by Dinamica EGO, between 2001 and 2015 are shown in Fig. 12. Broadly, the LULCC can be broken down into three categories: agricultural expansion, deforestation and degradation, and greening. Agricultural expansion is defined here as the change in the LULC category from a natural vegetation type to either the MODIS cropland or cropland and natural mosaic category. This LULCC is most prevalent across the northern and central portions of the domain. In West Africa, a loss of evergreen broadleaf forest is found along the coasts of Ghana and Côte d'Ivoire, with woody savanna significantly lost in Nigeria to cropland and natural vegetation mosaic. There are losses of savanna and grasslands to cropland in Ethiopia, Sudan, and South Sudan, while losses of woody savanna to cropland or natural vegetation occur in the western Republic of the Congo, western Democratic Republic of the Congo, and northwestern Angola. Deforestation and degradation, defined here as the transition from a more-forested MODIS natural vegetation type to a less-forested natural vegetation type, is commonly found in the southern and eastern portions of the domain. Major deforestation and degradation transitions include a loss of woody savanna to savanna (e.g., central An- 

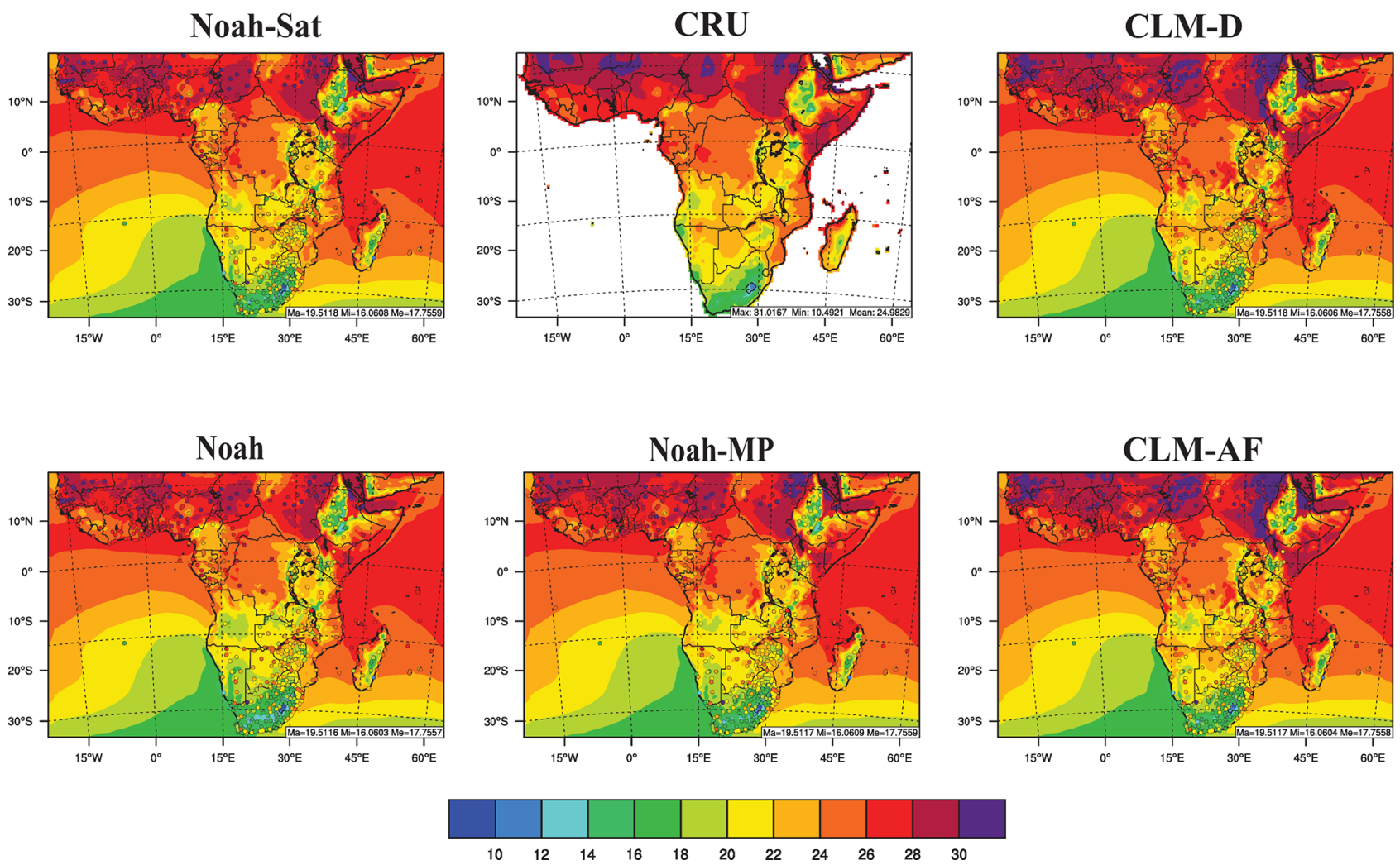

Figure 9. Year 2013 annual average $2 \mathrm{~m}$ temperature $\left({ }^{\circ} \mathrm{C}\right)$ from CRU and WRF simulations with five different LSMs. NCEI-ISD $2 \mathrm{~m}$ temperature observations are overlaid.

gola, Mozambique, Zambia, and Tanzania), loss of savanna to grasslands (e.g., Somalia and Kenya), and loss of savanna to open shrubland (e.g., Namibia, Botswana, and Madagascar). Finally, greening, defined here as the reclamation of the barren MODIS category by a vegetated category or a transition from a less-forested vegetation category to a moreforested vegetation category, is found along the Saharan border, the boundary of the Namib Desert, within the Horn of Africa, and along the eastern coast of Madagascar. While it is difficult to compare the LULCC predicted by Dinamica EGO to other African LULCC studies because these studies either use idealized LULCC (e.g., Abiodun et al., 2008; Wang et al., 2016) or do not simulate year to year changes, the increased agricultural expansion and deforestation and degradation are consistent with the LULCC seen in Otieno and Anyah (2012) for the period of 1986-2000.

\subsection{LULCC impact on surface properties}

A comparison of surface albedo changes between the LU01 and LUD simulations using the Noah, Noah-MP, CLM-D, and CLM-AF LSMs is shown in Fig. 13. The CLM-AF LSM is consistent with expected changes. Regions with a loss in vegetation from either agricultural expansion or deforestation and degradation experience surface albedo increases, while areas with greening experience albedo de- creases. However, Noah, Noah-MP, and CLM-D all deviate from expected changes because of errors and differences in their treatment of surface albedo. Additionally, due to the increased PFTs per LULC category in the CLM-AF treatment, there is greater overlap in PFTs between LULC categories, which results in albedo changes between vegetation categories that are less extreme than the other LSMs.

The LULCC-induced albedo changes in Noah deviate the most from the other LSMs. This is largely because of the erroneous treatment of woody savanna albedo as higher than croplands, cropland and natural vegetation mosaic, and savanna (Table S13). The result of this flawed treatment is an erroneous albedo decrease in areas where woody savanna is lost to agricultural expansion or deforested or degraded to savanna. While both CLM-D and Noah-MP also have inaccurate treatments for woody savanna, these LSMs do not have erroneous albedo responses. For Noah-MP, this is because the savanna and cropland categories are prescribed albedos less than woody savanna. In CLM-D, this is a result of the shrub leaf reflectance being less than that of grass and broadleaf deciduous trees. Noah-MP and CLM-D predict reductions in surface albedo for savanna to open shrubland transitions because both LSMs prescribe shrubs as having much lower leaf reflectance than grasses. In CLM-AF, the impact of lower shrub leaf reflectance is not as strong 

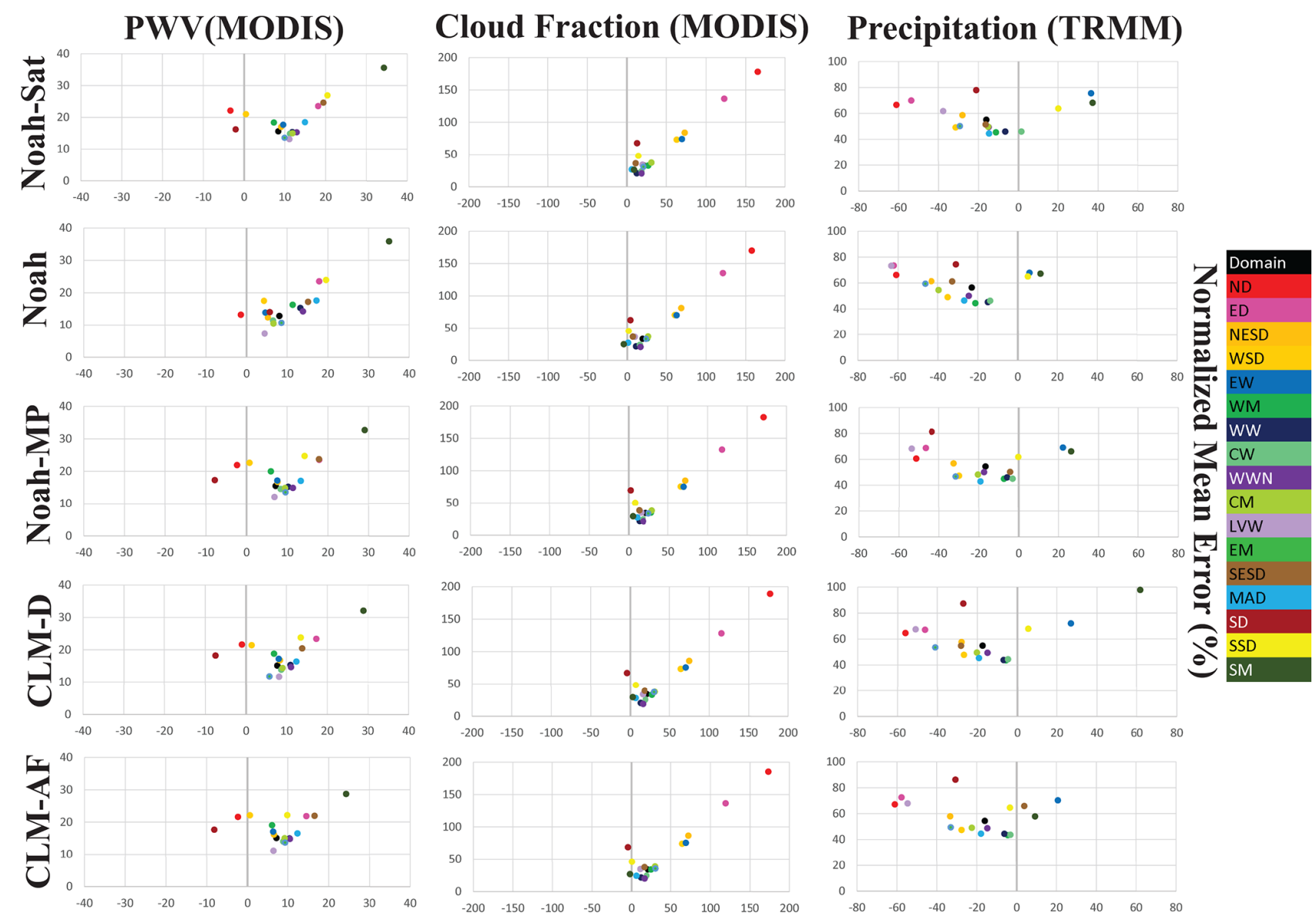

Normalized Mean Bias (\%)
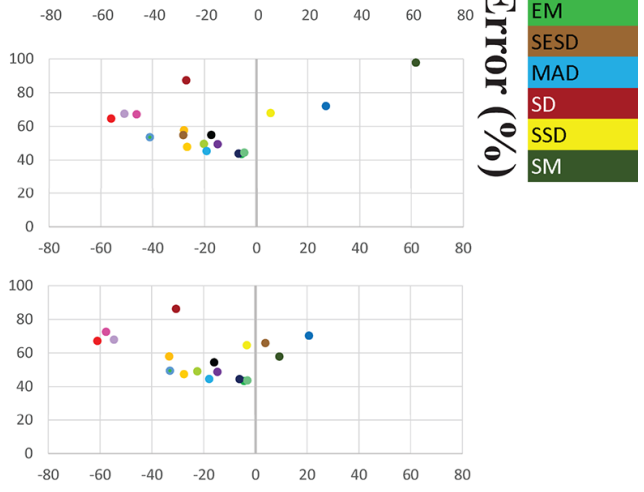

Figure 10. Normalized mean error and mean bias statistics of PWV, cloud fraction, and precipitation relative to observed MODIS PWV and cloud fraction and TRMM precipitation.

on the savanna to open shrubland transitions because open shrublands contain more bare soil than savannas (Table 2), leading to albedo increases for savanna to open shrubland transitions. Noah-MP also does not show a change in albedo from the greening around the Sahara because its flawed soil color treatment does not simulate a significant difference in the albedo of grasslands and bare soil in that region (Fig. 2).

Among LSMs, there is greater similarity in LAI (Fig. 14) than for surface albedo (Fig. 13). The LAI projections from LULCC for CLM-AF and Noah-MP have the same spatial pattern and direction with slightly different magnitudes. The projected LAI changes from CLM-D are also very similar to CLM-AF and Noah-MP across the northern half of the domain, but CLM-D has erroneous increases in LAI for woody savanna to savanna transitions. Again, these LAI errors are caused by erroneously treating woody savanna as a closed shrubland with a temporally uniform $1.0 \mathrm{~m}^{2} \mathrm{~m}^{-2}$ LAI (Table S3). The Noah LSM shows the greatest deviations from the other LSMs. This is mostly a result of erroneous increases in prescribed LAI values associated with agricultural expan- sion because croplands are prescribed higher LAI values than most natural vegetation. Additionally, the LAI of the woody savanna and savanna categories in Noah have the same prescribed values, and hence this transition shows no change (see Table S15).

\subsection{LULCC impact on $2 \mathrm{~m}$ temperature}

Changes in T2 between the LU01 and LUD simulations for each LSM are shown in Fig. 15. Locations that have the largest magnitude differences in T2 align with the more localized changes in LAI and albedo. Similar T2 patterns occur across the northern half of the domain when comparing Noah-MP, CLM-D, and CLM-AF simulations, while Noah predicts the most unique changes. To further investigate the LULCC impacts, annual average T2 differences are calculated for grid cells with different LULCC transitions (see Table 10). Additionally, we generate annual average differences of the surface energy budget and near surface temperature profiles for these grid cells, separately for daytime (SWDOWN $>0 \mathrm{~W} \mathrm{~m}^{-2}$ ) and nighttime 


\section{CRU}
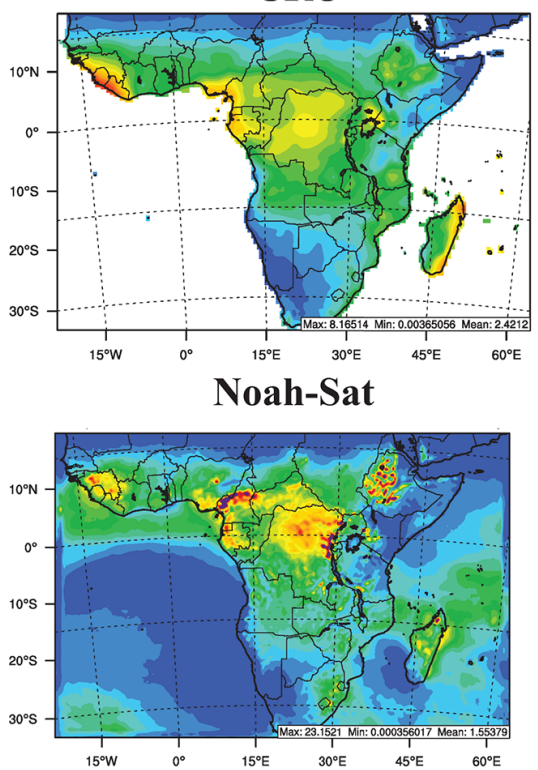

Noah

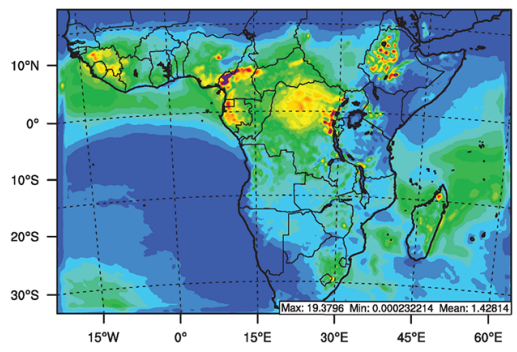

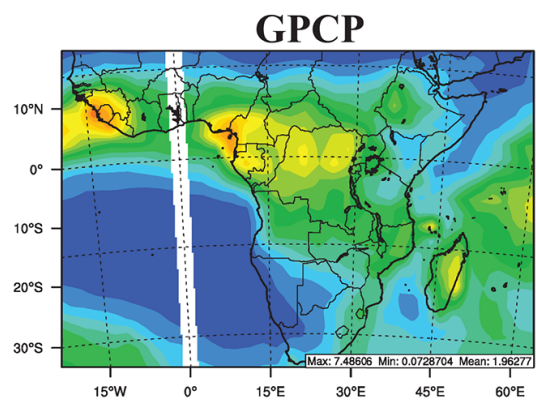
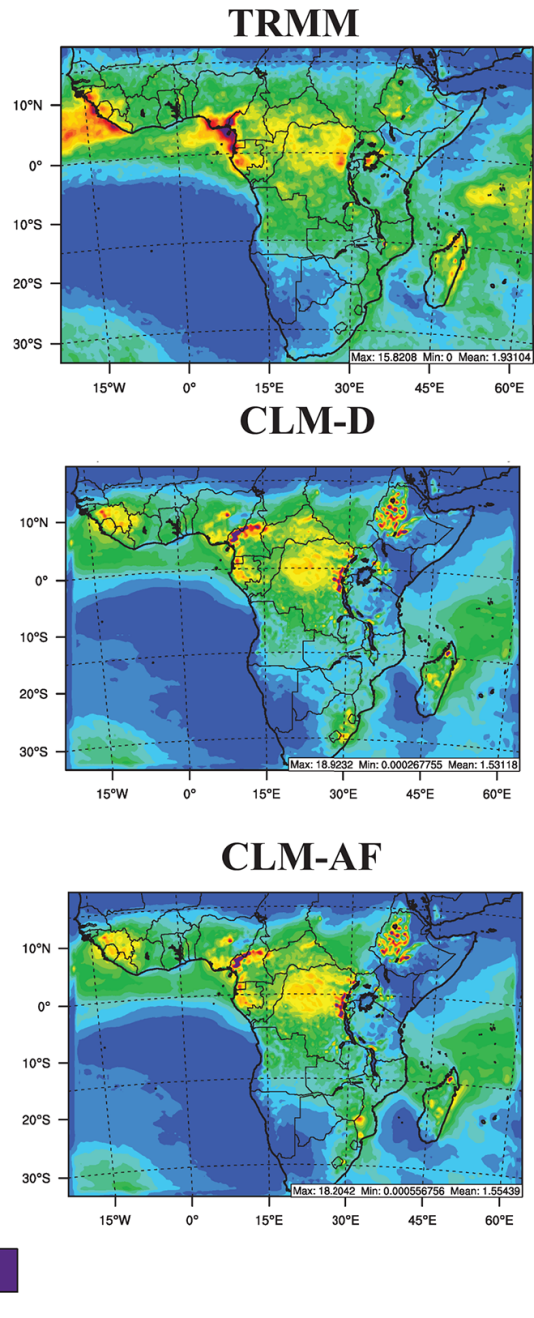

Figure 11. Year 2013 annual average precipitation rate $\left(\mathrm{mm} \mathrm{d}^{-1}\right)$ from CRU, GPCP, TRMM, and the five WRF LSM simulations.

( $\mathrm{SWDOWN}=0 \mathrm{~W} \mathrm{~m}^{-2}$ ) conditions. The diurnally split radiative flux differences for USRS, SWDOWN, upwelling longwave radiation at the earth's surface (ULRS), and GLW for each LSM are listed in Tables S16-S19. Additionally, the diurnally split surface heat flux differences for HFX, LH, and the ground fluxes (GRDFLX) are listed in Tables S20-S23. Lastly, the diurnally split surface temperature profile differences for surface skin temperature (TSK), T2, lowest model layer temperature (TATM), and the surface to lowest model layer vertical temperature gradient (TGSATM) for each LSM are listed in Tables S24-S27.

Agricultural expansion induces annual average localized warming of $\sim 0.1-0.2^{\circ} \mathrm{C}$ using Noah-MP, CLM-D, and CLM-AF, but a localized cooling of $-0.12^{\circ} \mathrm{C}$ using Noah. The cooling from Noah for most agricultural expansion transitions occurs in response to erroneous increases in LAI (Fig. 14) that result in erroneous daytime LH increases and evaporative cooling (Table S23). However, in the transition of evergreen broadleaf forest to mosaic cropland along the coasts of Ghana and Côte d'Ivoire the LAI transition follows the other LSMs (Fig. 14), indicating that this cooling is the result of excessive daytime average USRS increases of $37.3 \mathrm{~W} \mathrm{~m}^{-2}$ (Table S19) from surface albedo increases (Fig. 13). In the other LSMs, this evergreen broadleaf forest to mosaic cropland transition results in the strongest warming response from agricultural expansion, with an average $0.6^{\circ} \mathrm{C}$ warming using Noah-MP and $\sim 1.3-1.4^{\circ} \mathrm{C}$ of warming using CLM-D and CLM-AF. This warming is the result of reduced daytime evaporative cooling, as evidenced by the largest daytime LH reductions of any LULCC transition (Tables S20-S22). However, this warming is somewhat indirect, as the greatest $\mathrm{T} 2$ increases occur during the nighttime. This is because the reduced daytime LH leads to greater land surface heat storage via the GRDFLX, which is then released at night, heating the atmosphere. For most other agricultural expansion transitions, CLM-AF predicts nighttime warming consistent with reduced daytime LH and increased daytime GRDFLX, as described above. The exception is the grassland 

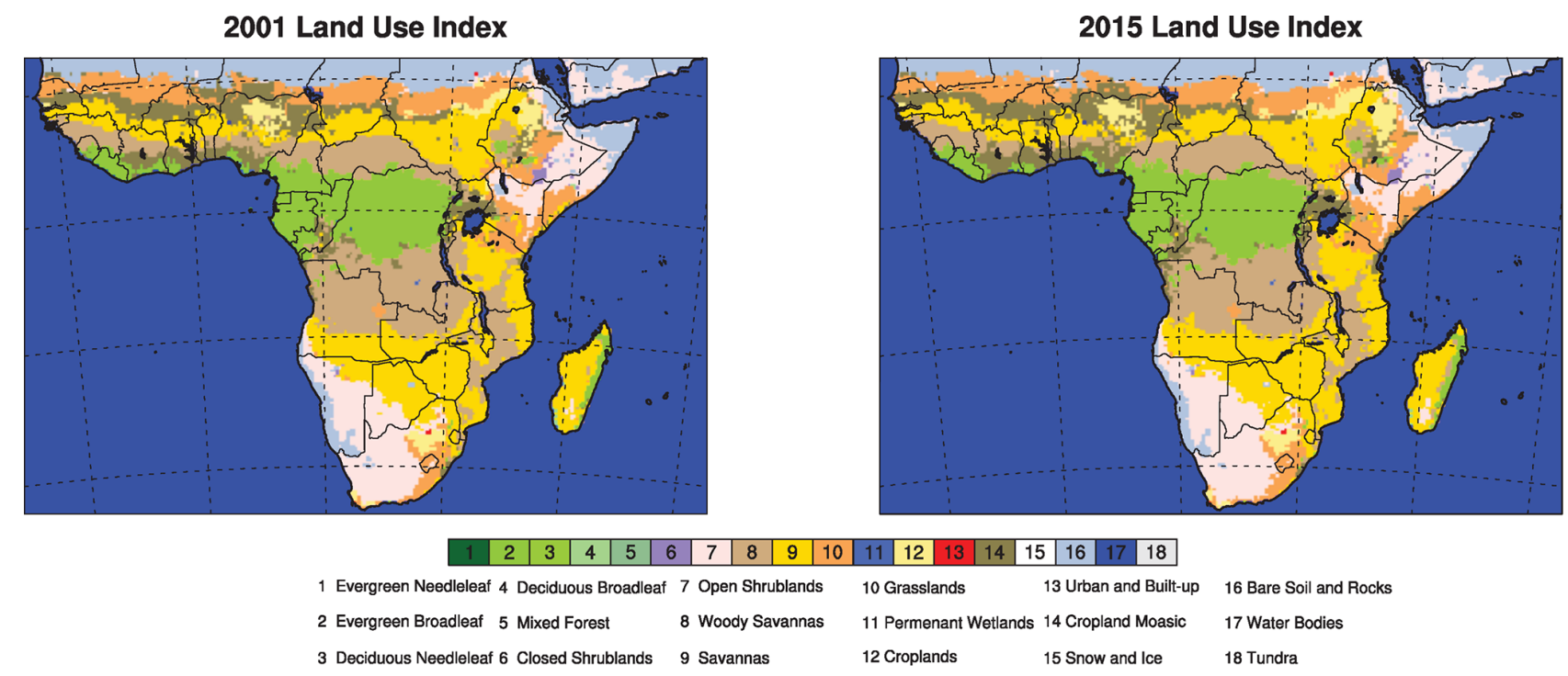

\section{Land Use Mask}

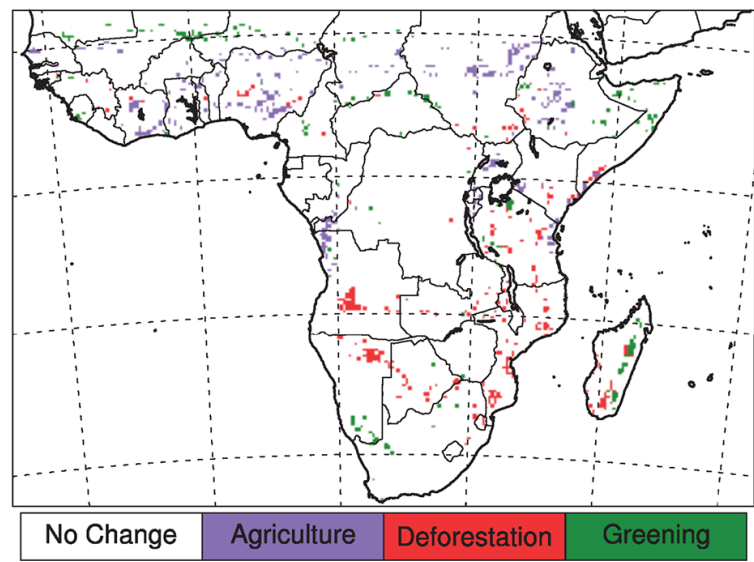

Figure 12. Processed MODIS land use and land cover categories for 2001, simulated categories for 2015, and grid cells that experience transitions due to agricultural expansion, deforestation or degradation, and greening.

to mosaic cropland transition, where most warming occurs during the daytime due to reductions in USRS from albedo increases that increase TSK and HFX warming the atmosphere (Tables S16, S20, and S24). Noah-MP predicts less warming with no clear signal as to the mechanism behind the warming. This is caused by the relative insensitivity of LH (Table S21) to agricultural expansion in Noah-MP, which allows other processes such as surface albedo changes, biogeophysical effects of RL changes (Winckler et al., 2019; Breil et al., 2020), and other secondary feedbacks to compensate each other, resulting in a weaker climate signal. The behavior of CLM-AF is consistent with the global remote sensing work of Duveiller et al. (2018), which indicates losses in latent heat flux for all natural vegetation to cropland transitions. CLM-D has many T2 changes similar to CLM-AF with some exceptions. The erroneous treatment of albedo for woody savanna in CLM-D, being too high, leads to exces- sive daytime increases in USRS of $29.8 \mathrm{~W} \mathrm{~m}^{-2}$ (Table S18) for the transitions from woody savanna to mosaic cropland, which cools the surface (Table S26), reduces the HFX (Table S22), and results in minor cooling. In the other transitions from grasslands to different types of cropland, CLM-D does not have as strong a daytime LH reduction as CLM-AF, leading to either similar or weaker T2 warming that may be affected more by feedbacks from other model processes.

Deforestation and degradation grid cells experience an average $0.22^{\circ} \mathrm{C}$ warming using CLM-AF, while the remaining LSMs predict almost no change in $\mathrm{T} 2$ for these grid cells (e.g., $-0.03-0.04^{\circ} \mathrm{C}$ ). The strong warming signal in CLM-AF can potentially come from multiple mechanisms, but in all deforestation transitions the reduced daytime LH and increased daytime GRDFLX that leads to nighttime T2 warming appears to dominate (Tables S20 and S24). Unlike agricultural expansion, deforestation in CLM-AF causes de- 

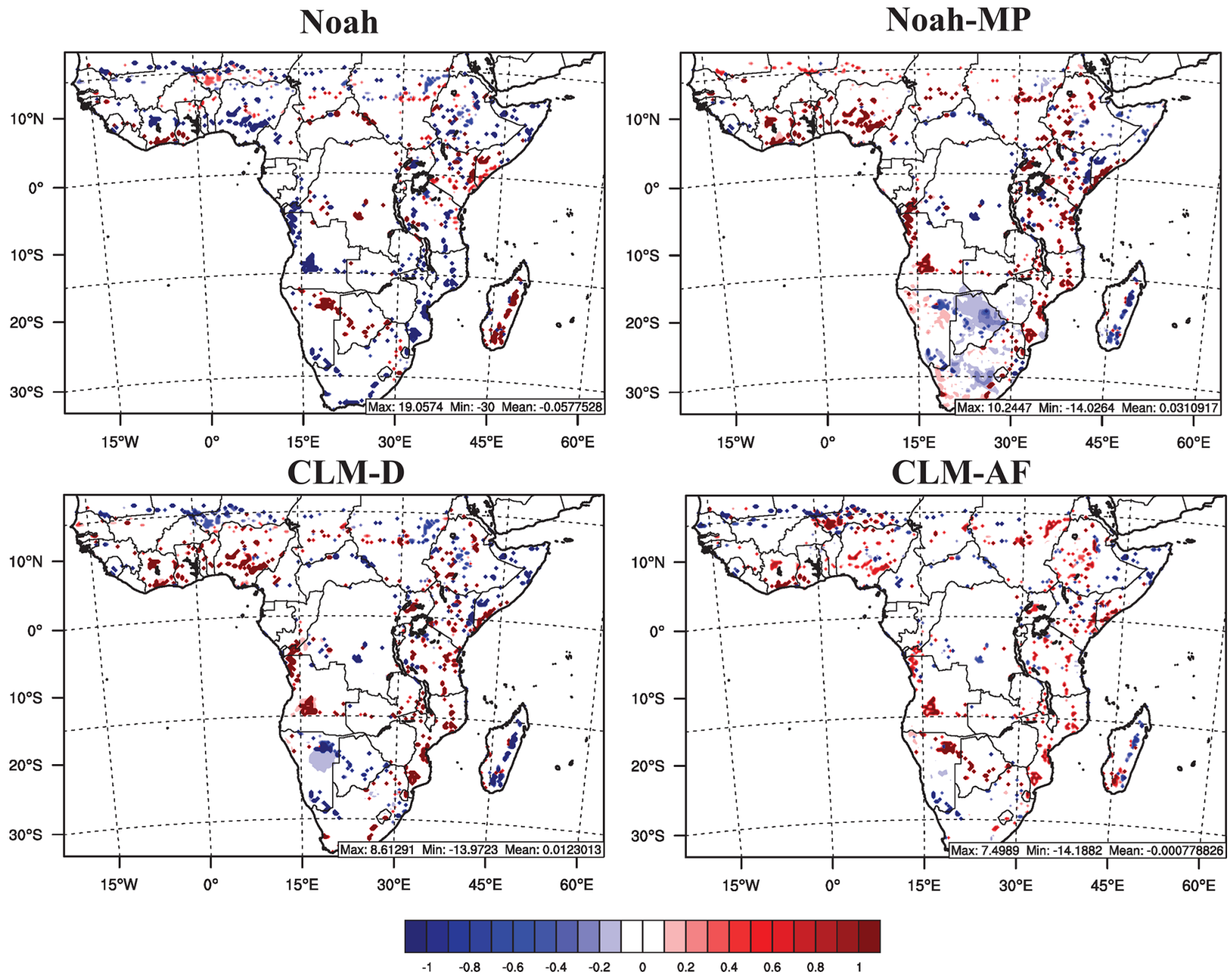

Figure 13. Differences in albedo (\%) between LUD and LU01 (LUD-LU01) simulations using Noah, Noah-MP, CLM-D, and CLM-AF.

creases in daytime HFX. This could potentially be the result of biogeophysical effects of reduced RL making surface heating less efficient or it may be related to the relatively large increases in USRS from deforestation reducing energy input. In Noah-MP, smaller changes in evapotranspiration coupled with greater enhancements in surface reflectance for the woody savanna to savanna transition lead to little to no climate signal in T2. For the other deforestation transitions, Noah-MP predicts daytime TSK increases unlike CLM-AF (Tables S24 and S25), but little to no change in annual average T2. This may be related to the effects of RL reductions reducing daytime HFX (Table S21) and increasing TGSATM (Table S25). The reduced heating efficiency coupled with reduced available energy from either increased daytime USRS or reduced daytime SWDOWN leads to small daytime $\mathrm{T} 2$ cooling in these transitions that compensates any nighttime warming from reduced evapotranspiration. In CLM-D, the overall small change in annual average T2 from deforestation and degradation is due to offsetting changes in different LULCC transitions. This offsetting behavior is primarily related to the woody savanna albedo and LAI errors that when combined do not substantially reduce the daytime LH $\left(-0.1 \mathrm{~W} \mathrm{~m}^{-2}\right)$ and excessively enhance daytime USRS $\left(18.9 \mathrm{~W} \mathrm{~m}^{-2}\right)$ in grid cells with woody savanna to savanna transitions (Tables S22 and S26). Since woody savanna to savanna transitions comprise a substantial portion of the total deforestation and degradation grid cells, this signal cancels the warming from other transitions. The warming from CLM-D in the other deforestation transitions appears somewhat similar to CLM-AF. The daytime LH reduction and nighttime T2 increase mechanism appears to be responsible for the warming in the savanna to grassland transition. However, the nighttime warming in the savanna to open shrubland transition appears to be related to reduced daytime HFX that increases the daytime GRDFLX, which could be related to either reductions in USRS from albedo reductions or biogeophysical impacts from reduced RL. Noah also experiences offsetting impacts from different deforestation and degrada- 

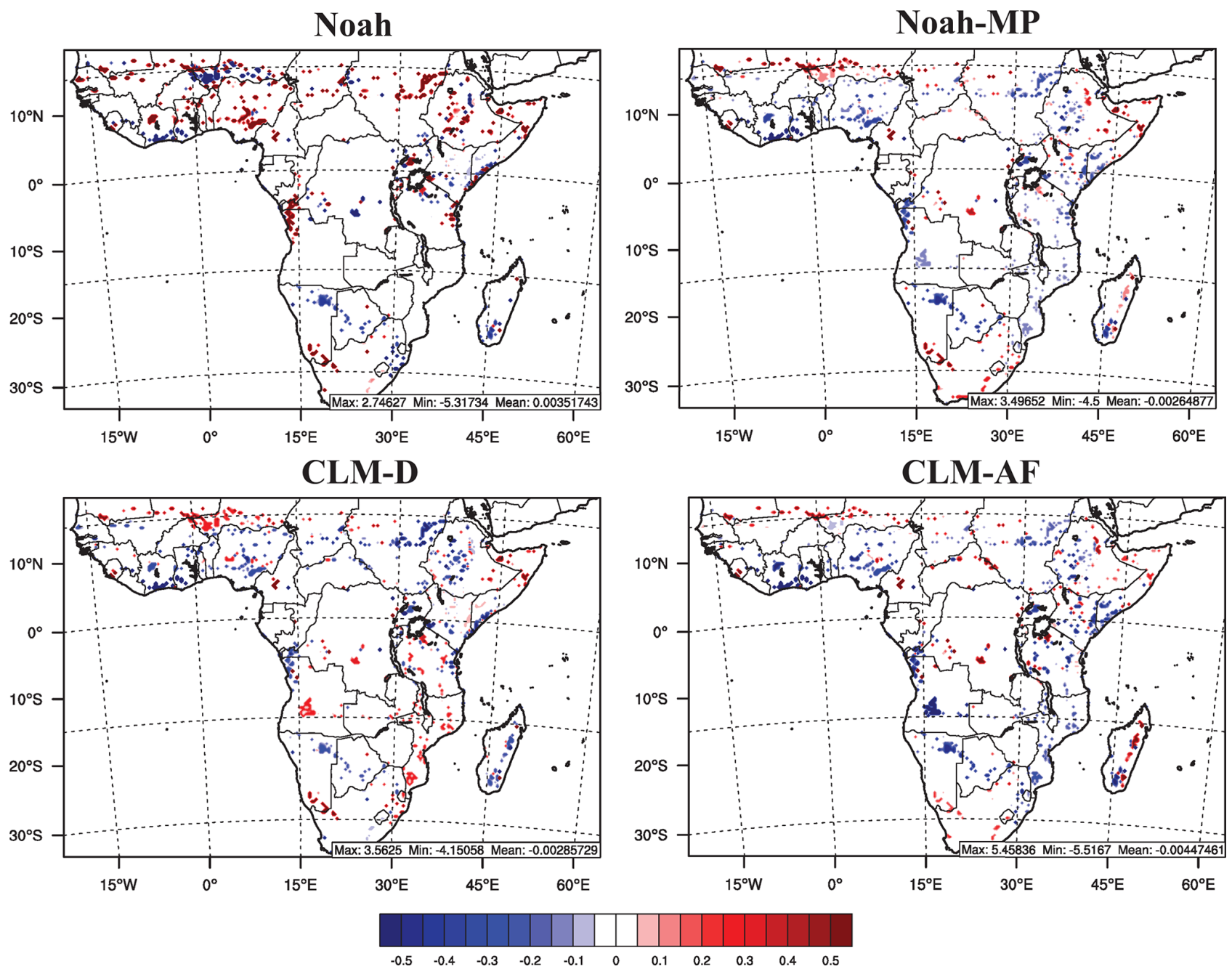

Figure 14. Differences in leaf area index $\left(\mathrm{m}^{2} \mathrm{~m}^{-2}\right)$ between the LUD and LU01 (LUD-LU01) simulations using Noah, Noah-MP, CLM-D, and CLM-AF.

tion transitions. Noah predicts annual average warming for the woody savanna to savanna transitions. This is caused primarily by large daytime decreases in USRS $\left(-35.0 \mathrm{~W} \mathrm{~m}^{-2}\right)$ and increases in HFX $\left(23.9 \mathrm{~W} \mathrm{~m}^{-2}\right)$, which increases daytime T2 despite decreases in daytime TSK (Tables S19, S23, and S27). This suggests that the warming in this transition for Noah is primarily related to either excessive surface albedo changes or the erroneous increase in RL in this transition that increases the heating efficiency of the atmosphere. Noah predicts cooling $\mathrm{T} 2$ for the other dominant deforestation and degradation transitions, primarily due to albedo reductions that are not countered by any substantial reduction in LH.

Grid cells that experience greening have annual average cooling using Noah-MP, CLM-D, and CLM-AF (Table 10). CLM-AF and CLM-D predict similar cooling $(-0.41$ and $-0.33^{\circ} \mathrm{C}$, respectively). In the transitions from barren lands to vegetation, the primary mechanism responsible for the cooling in both LSMs is enhanced daytime LH that reduces the daytime GRDFLX, which reduces nighttime heat release. In the grassland to savanna transition, the cooling for both LSMs results from reduced daytime GRDFLX that appears to be related to either other model feedbacks that reduce daytime SWDOWN or enhanced daytime HFX via the biogeophysical impacts of increased RL. In CLM-AF, the savanna to woody savanna transition experiences cooling via the increased daytime LH and associated nighttime cooling mechanism discussed above. However, CLM-D predicts slight annual average warming due to the erroneously large reduction in daytime USRS of $-18.7 \mathrm{~W} \mathrm{~m}^{-2}$ (Table S18), which is in turn due to the treatment of woody savanna as closed shrubland in CLM-D. This large reduction in USRS overwhelms the daytime LH increases and increases the daytime GRDFLX, causing nighttime warming. Noah-MP predicts slightly weaker annual average cooling $\left(-0.13^{\circ} \mathrm{C}\right)$ from greening. The mechanisms responsible for the cooling in Noah-MP for most transitions are similar to CLM-AF with similar day- 
Table 10. Annual average $2 \mathrm{~m}$ temperature change $\left({ }^{\circ} \mathrm{C}\right)$ in WRF grid cells that experience LULCCs between 2001 and $2010-2015$.

\begin{tabular}{lrrrr}
\hline Transition & Noah & Noah-MP & CLM-D & CLM-AF \\
\hline Agricultural expansion* & -0.12 & 0.1 & 0.1 & 0.17 \\
10 to 12 & -0.09 & 0.16 & 0.18 & 0.17 \\
2 to 14 & -0.3 & 0.6 & 1.34 & 1.38 \\
8 to 14 & -0.06 & 0.01 & -0.12 & 0.15 \\
10 to 14 & -0.1 & 0.06 & 0.03 & 0.07 \\
\hline Deforestation and degradation* & 0.04 & -0.01 & -0.03 & 0.22 \\
8 to 9 & 0.17 & -0.03 & -0.22 & 0.18 \\
9 to 7 & -0.16 & -0.04 & 0.12 & 0.36 \\
9 to 10 & -0.11 & -0.05 & 0.1 & 0.11 \\
\hline Greening* & 0.02 & -0.13 & -0.33 & -0.41 \\
9 to 8 & -0.12 & 0.0 & 0.08 & -0.13 \\
10 to 9 & 0.18 & -0.02 & -0.28 & -0.26 \\
16 to 7 & -0.01 & -0.13 & -0.39 & -0.40 \\
16 to 10 & 0.09 & -0.2 & -0.81 & -0.8 \\
\hline
\end{tabular}

* Shows the average difference for a broad class of LULCC, followed by the average difference in the major MODIS LULCC transitions that comprise that class. MODIS land use categories are as follows: 2 : evergreen broadleaf forest; 7: open shrublands; 8: woody savanna; 9: savannas; 10: grasslands; 12: croplands; 14: cropland and natural mosaic; 16: barren or sparsely vegetated.

Table 11. Annual average precipitation rate change $\left(\mathrm{mm} \mathrm{d}^{-1}\right)$ in WRF grid cells that experience LULCCs between 2001 and 2015.

\begin{tabular}{|c|c|c|c|c|}
\hline Transition & Noah & Noah-MP & CLM-D & CLM-AF \\
\hline Agricultural expansion* & 0.02 & -0.13 & -0.08 & -0.03 \\
\hline 10 to 12 & 0.02 & -0.04 & 0.05 & -0.02 \\
\hline 2 to 14 & -0.12 & -0.25 & -0.45 & -0.38 \\
\hline 8 to 14 & 0.07 & -0.18 & -0.10 & 0.00 \\
\hline 10 to 14 & 0.04 & -0.01 & 0.04 & -0.02 \\
\hline Deforestation and degradation* & 0.02 & -0.01 & -0.04 & -0.08 \\
\hline 8 to 9 & 0.07 & -0.03 & -0.01 & -0.04 \\
\hline 9 to 7 & -0.05 & 0.05 & 0.12 & -0.05 \\
\hline 9 to 10 & -0.01 & -0.01 & -0.02 & -0.04 \\
\hline Greening* & 0.00 & 0.03 & 0.15 & 0.05 \\
\hline 9 to 8 & -0.02 & 0.03 & 0.14 & -0.03 \\
\hline 10 to 9 & -0.03 & 0.06 & 0.01 & 0.02 \\
\hline 16 to 7 & -0.01 & 0.02 & 0.05 & 0.00 \\
\hline 16 to 10 & 0.05 & -0.01 & 0.02 & 0.02 \\
\hline
\end{tabular}

time LH increases, except the daytime GRDFLX reductions are not as large (Tables S20-S21). However, because NoahMP does not predict any change in LAI between savanna and woody savanna, this transition has little change in $\mathrm{LH}$ and a negligible change in T2. Finally, the Noah simulations continue to be an outlier with almost no change $\left(0.02^{\circ} \mathrm{C}\right)$ due to offsetting inaccurate surface property changes in different greening LULCC transitions.

The three types of transition-based changes discussed above lead to very different spatial T2 changes (Fig. 15). The
T2 changes using the Noah LSM are largely incoherent due to various surface parameter errors. The T2 changes using Noah-MP are much weaker than CLM-D or CLM-AF because only the starkest LULCC transitions using Noah-MP impact local temperatures (i.e., transition from broadleaf evergreen forest to mosaic cropland within West Africa, transition from grassland to cropland in northeastern Africa, and transition from barren soil to grassland along the Sahara border). The simulated T2 changes associated with LULCC in CLM-D and CLM-AF are largely the same above the Equa- 

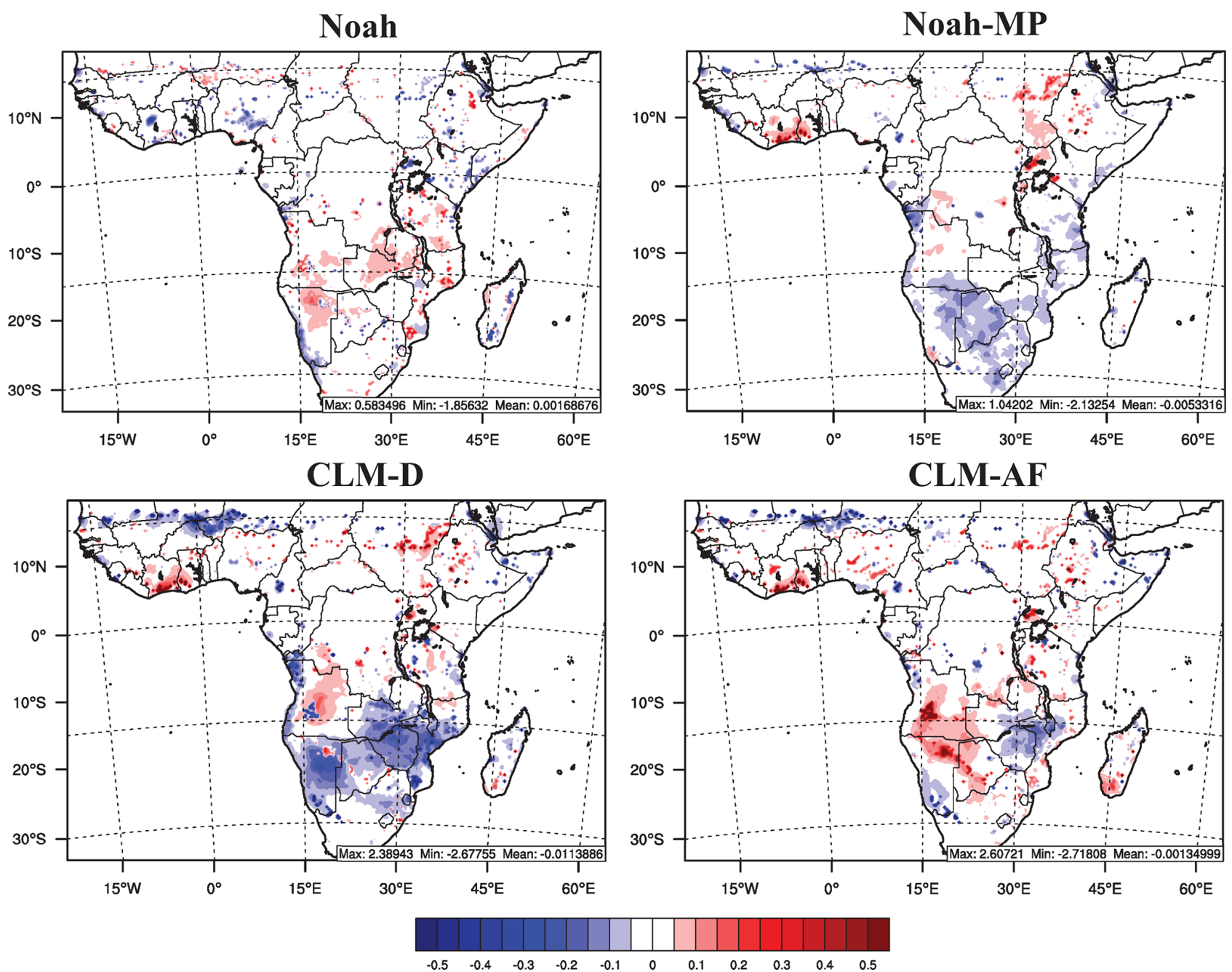

Figure 15. Differences in $2 \mathrm{~m}$ temperature $\left({ }^{\circ} \mathrm{C}\right.$ ) between the LUD and LU01 (LUD-LU01) simulations using Noah, Noah-MP, CLM-D, and CLM-AF.

tor, but improper treatment of woody savannas and Southern Hemisphere growing cycles result in erroneous cooling in southern Africa using CLM-D. CLM-AF is the only LSM that captures warming from agricultural expansion in Nigeria, as well as the large-scale annual average warming associated with deforestation and degradation in southwestern Africa (e.g., Angola, Namibia, and Botswana).

\subsection{LULCC impact on precipitation}

In general, PRE changes between the LU01 and LUD simulations for each LSM (Fig. 16, Table 11) are more regional and much more chaotic than changes in temperature. However, there are a few localized changes in PRE from LULCC. Along the coast of Ghana and Côte d'Ivoire, the lost broadleaf evergreen forest decreases PRE in all four LSMs by $0.12-0.45 \mathrm{~mm} \mathrm{~d}^{-1}$ on average. This is in response to reduced moisture availability due to reduced evapotranspiration, enhanced stability from increased surface albedo, and possible reduced moisture convergence from reduced surface roughness. Additionally, both Noah-MP and CLM-D also predict reduced PRE for grid cells that experience woody savanna to mosaic cropland transitions (e.g., Nigeria), due to enhanced atmospheric stability from erroneous reductions in surface albedo.

The most significant regional PRE changes occur within southern Africa. During the southern Africa rainy season (October-March), the Angola Low is assumed to form in response to dry convection processes associated with surface heating in Angola (Mulenga, 1998); however, the exact processes responsible for the Angola Low's formation are poorly understood (Munday and Washington, 2017). The strength and position of the Angola Low have been shown to significantly alter the gradients and magnitude of precipitation over southern Africa (e.g., Cook et al., 2004; Cretat et al., 2019). All LSMs predict excess heating from deforestation and degradation between the LU01 and LUD simulations in 

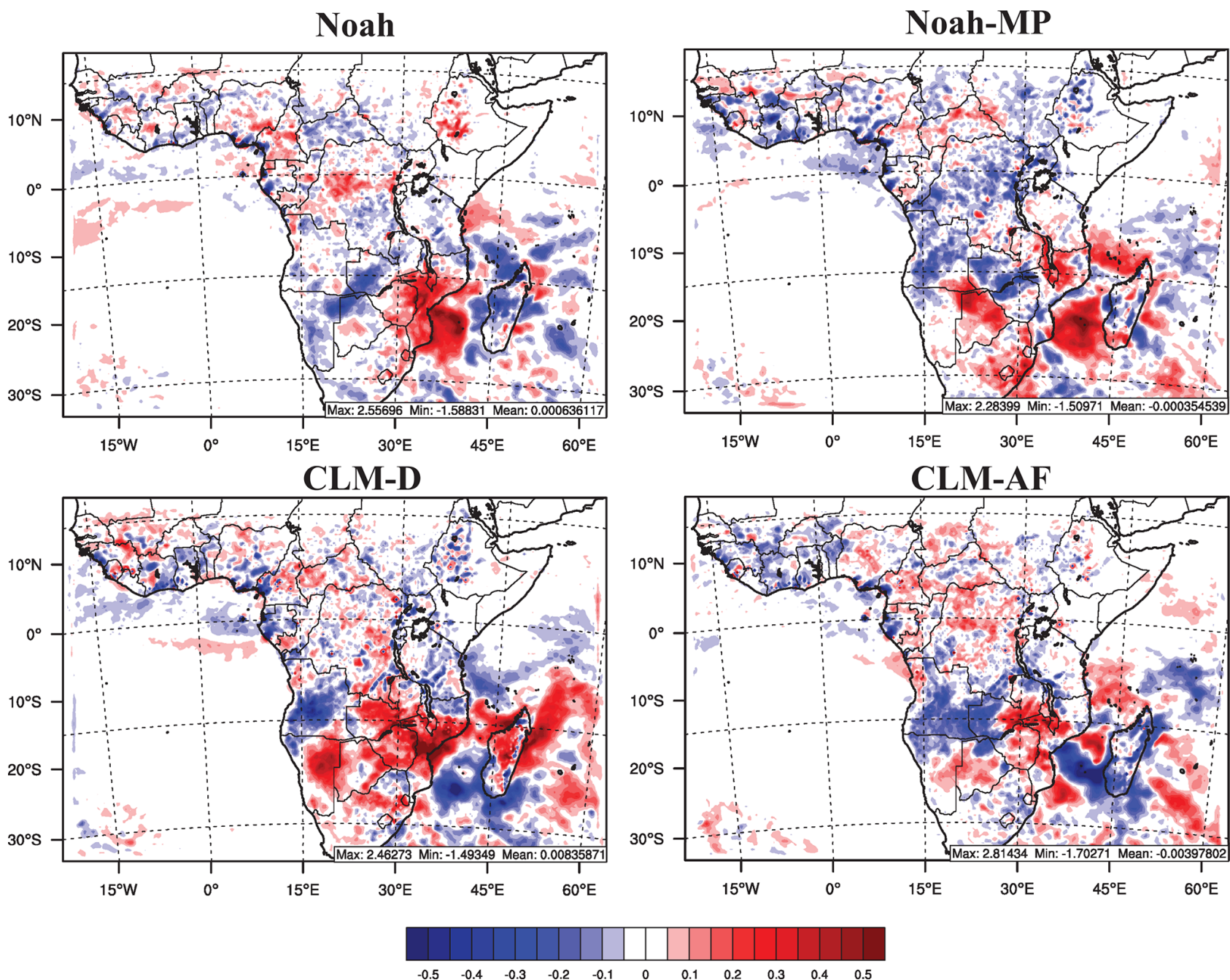

Figure 16. Differences in precipitation rate $\left(\mathrm{mm} \mathrm{d}^{-1}\right)$ between the LUD and LU01 (LUD-LU01) simulations using Noah, Noah-MP, CLM-D, and CLM-AF.

Angola. This heating results in a persistent reduction of surface sea level pressure (Fig. S18) during southern Africa's rainy season (DJF) within Angola and nearby countries. The sea level pressure changes strengthen either the Angola Low or the associated Kalahari thermal low, which induces a stronger cyclonic circulation (Fig. S19) over southern Africa that opposes moist onshore flow over Mozambique. This reduces moisture transport into southwestern Africa, leads to drying in Angola and surrounding areas, and enhances moisture convergence in southeastern Africa, increasing PRE in Mozambique and surrounding areas. The exact location and strength of this LULCC-induced PRE climate signal varies between LSMs due to differences in the strength and spatial location of maximum heating, but this feature appears robust.

\section{Summary and conclusions}

In this work the applicability of commonly used WRF LSMs (i.e., Noah, Noah-MP, and CLM-D) with WRF's default MODIS LULC data is explored in Sub-Saharan Africa. Each default WRF LSM is found to have unique deficiencies in representing African surface parameters including (1) significantly overestimated surface albedo and underestimated RL using the Noah LSM, (2) the same underestimated RL as Noah using Noah-Sat, (3) significantly underestimated surface albedo in arid areas due to inaccurate soil albedo treatments using Noah-MP, and (4) geographically invariable surface parameters using CLM-D that make it unsuitable for use outside the Northern Hemisphere midlatitudes. Additionally, all default WRF LSMs inaccurately treat the MODIS woody savanna land use category as closed shrubland. These deficiencies likely have a minimal impact on simulations in middle or high latitudes of the Northern Hemisphere but lead to 
substantial inaccuracies in Africa. Consequently, we developed a version of the CLM LSM in WRF that more accurately represents these properties in Africa (CLM-AF).

Despite clear deficiencies in surface parameters, all WRF LSMs reasonably capture the spatial pattern and magnitudes of precipitation and $\mathrm{T} 2$. The only detectable impact of inaccurate surface parameters is the slightly stronger cold and dry bias using the Noah LSM that occurs because of its overestimated albedo. The WRF model with each LSM reasonably captures the climate of Sub-Saharan Africa, despite errors with cloud parameters and radiative forcing that are common to most climate models (e.g., Lauer and Hamilton, 2013).

Regardless of the similar meteorological performance, the land surface parameter errors amongst the default WRF LSMs substantially impact the magnitude and direction of LULCC-induced changes in temperature and (to a lesser extent) localized changes in precipitation. The surface parameters in the Noah LSM and CLM-D are the most flawed, and as a result neither LSM is suitable for LULCC experiments in Africa. Additionally, great care should be taken when utilizing these LSMs for other scientific applications in these regions. Noah-MP is least flawed of the default LSMs and with several updates may also be suitable for use in tropical regions (e.g., Spera et al., 2018).

Although several of the default LSMs produced erroneous LULCC-induced climate signals, there are several common features that stand out as potentially robust. Losses of broadleaf evergreen forest along the coasts of Ghana and Côte d'Ivoire to agricultural expansion between 2001 and 2015 appear to have caused warming and drying in this region for LSMs that accurately treat this transition. Additionally, warming from deforestation in Angola, Namibia, and Botswana is modeled to have altered the DJF average atmospheric circulations in this region, decreasing precipitation in southwestern Africa and increasing precipitation in southeastern Africa. Important mechanistic differences also stand out between the Noah-MP and CLM-AF LSMs. Noah-MP predicts little change in LH between vegetated to vegetated LULCC transitions unless they are particularly stark (e.g., broadleaf evergreen forest to mosaic cropland), while CLMAF consistently predicts $\mathrm{LH}$ change between vegetation transitions resulting in stronger thermal changes from gains or losses in evaporative cooling. This indicates that the accuracy of LH sensitivity in LSMs to LULCC is crucial to the accuracy of LULCC climate signal predictions in the tropics. Additionally, the incoherent temperature and moisture climate signals in the Noah LSM indicate that albedo accuracy may play a role in determining whether evapotranspiration, RL change, or shortwave radiative effects will dominate LULCC climate signals.

Overall, this study serves as a cautionary tale to illustrate that proficient meteorological performance can mask severe flaws in model treatments and that special care is needed to evaluate LSM parameters when conducting LULCC studies in Africa. While this study focuses on Africa, we expect that these LSMs would encounter similar problems in applications to other regions of the tropics or Southern Hemisphere. More work is required by the scientific and model development communities to not only improve meteorological model processes but also to ensure that these scientific improvements are applicable to as many climate regimes and localities as possible. Additionally, this work documents the development of the WRF CLM-AF configuration for use in LULCC studies of Sub-Saharan Africa. Future companion papers will explore the climate change signals attributable to LULCC in Sub-Saharan Africa, their statistical significance, and their impact on air quality. This development is a first step towards better global LULC representations in WRF, but additional improvements are needed to accurately represent land surface and vegetation parameters across the various global climate regimes.

Code and data availability. The default WRF model is publicly available for download from the WRF website (https: //www2.mmm.ucar.edu/wrf/users/download/get_source.html,

last access: 20 May 2021, Skamarock and Klemp, 2008). The CLM-AF code at https://doi.org/10.15139/S3/DZ7XS3 (Glotfelty et al., 2020a), additional code to recreate the experiments shown here at https://doi.org/10.15139/S3/W2LWJV and https://doi.org/10.15139/S3/JGIQOE (Glotfelty et al., 2020b, c), the African bio-climate region data at https://doi.org/10.15139/S3/WHNILT (Glotfelty et al., 2020d), the Dinamica EGO-generated land use and land cover data at https://doi.org/10.15139/S3/BEA55Z (Glotfelty et al., 2020e), and instructions for using this code and input data at https://doi.org/10.15139/S3/MQ8KNS (Glotfelty et al., 2020f) are all available on the UNC Dataverse Archive (https://dataverse.unc.edu/dataverse/CLM-AF1, last access: 12 June 2020). The ERA-Interim reanalysis data for meteorological initial and boundary conditions can be found on the NCAR Research Data Archive website (https://doi.org/10.5065/D6CR5RD9, ECMWF, 2009). All observational data used to evaluate the WRF model are publicly available from the websites listed in Table 8 . The Climatic Research Unit (CRU) Time-Series (TS) version 4.01 of high-resolution gridded data of month-by-month variation in climate (January 1901-December 2016) can be found online at https://doi.org/10.5285/58a8802721c94c66ae45c3baa4d814d0

(Harris and Jones, 2017) with the specific version 4.02 found at https://crudata.uea.ac.uk/cru/data/hrg/cru_ts_4.02 (last access: 13 November 2020). The CERES-EBAF monthly mean surface data can be found online at https://doi.org/10.5067/TERRA+AQUA/CERES/EBAF-

SURFACE_L3B004.0, while the top of the atmosphere data can be found online at https://doi.org/10.5067/TERRA+AQUA/CERES/EBAF-

TOA_L3B004.0 (NASA, 2017a, b). The TRMM level 3 $3 \mathrm{~h}$ precipitation product can be found online at https://doi.org/10.5067/TRMM/TMPA/3H/7 (TRMM, 2011). The MODIS MOD08 Atmosphere Level 3 product can be found online at https://doi.org/10.5067/MODIS/MOD08_M3.061 (Platnick, 2017). The GPCP precipitation data (Adler et al., 2003) are provided by the NOAA/OAR/ESRL PSL, Boulder, Colorado, USA, 
from their website https://psl.noaa.gov/data/gridded/data.gpcp.html (last access: 15 October 2018). The hourly NCEI-ISD global surface meteorology observation data (Smith et al., 2011) are provided by the NOAA NCEI from their website https://www.ncei.noaa.gov/data/global-hourly (last access: 26 November 2018).

Supplement. The supplement related to this article is available online at: https://doi.org/10.5194/gmd-14-3215-2021-supplement.

Author contributions. TG developed and tested the CLM-AF code, conducted all WRF simulations, and wrote the manuscript. JB and JJW provided scientific input on the code development and experimental design. JB processed and refined the manuscript figures. DRM and AG designed the land use modeling framework. DRM generated all the land use and land cover modeling products. All authors reviewed and modified the manuscript.

Competing interests. The authors declare that they have no conflict of interest.

Acknowledgements. Special thanks are due to Tanya Spero, Jonathan Pleim, and Limei Ran of the United States Environmental Protection Agency for their valuable feedback on the development of CLM-AF. Computational resources were provided by Extreme Science and Engineering Discovery Environment (XSEDE) (Towns et al., 2014), which is supported by National Science Foundation (grant no. ACI-1548562). Simulations were conducted on the XSEDE stampede2 cluster provided by the Texas Advanced Computing Center, through allocation TG-ATM180014.

Financial support. This research has been supported by the National Science Foundation, Directorate for Geosciences (grant no. CNH-1617359) and the Foundation for the National Institutes of Health (grant no. T32ES007018).

Review statement. This paper was edited by Christoph Müller and reviewed by two anonymous referees.

\section{References}

Abiodun, B. J., Pal, J. S., Afiesimama, E. A., Gutowski, W. J., and Adedoyin, A.: Simulation of West African monsoon using REgCM3 Part II: impacts of deforestation and desertification, Theor. Appl. Climatol., 93, 245-261, https://doi.org/10.1007/s00704-007-0333-1, 2008.

Adeniyi, M. O. and Dilau, K. A.: Assessing the link between Atlantic Nino 1 and drought over Africa using CORDEX regional climate models, Theor. Appl. Climatol., 131, 937-949, https://doi.org/10.1007/s00704-016-2018-0, 2018.
Adler, R. F., Huffman, G. J., Chang, A., Ferraro, R., Xie, P., Janowiak, J., Rudolf, B., Schneider, U., Curtis, S., Bolvin, D., Gruber, A., Susskind, J., Arkin, P., and Nelkin, E.: The Version-2 Global Precipitation Climatology Project (GPCP) Monthly Precipitation Analysis (1979-Present), J. Hydrometeorol., 4, 1147-1167, https://doi.org/10.1175/15257541(2003)004<1147:TVGPCP>2.0.CO;2, 2003.

Alaka, G. J. and Maloney, E. D.: Internal intraseasonal variability of the West African Monsoon in WRF, J. Climate, 30, 5815-5832, https://doi.org/10.1175/JCLI-D-16-0750.1, 2017.

Argent, R., Sun, X., Semazzi, F., Xie, L., and Liu, B.: The development of a customization framework for the WRF model of the Lake Victoria Basin, Eastern Africa on Seasonal Timescales, Adv. Meteorol., 2015, 653473, https://doi.org/10.1155/2015/653473, 2015.

Arnault, J., Knoche, R., Wei, J., and Kuntsmann, H.: Evaporation tagging and atmospheric water budget analysis with WRF: A regional precipitation recycling study for West Africa, Water Resour. Res., 52, 1544-1567, https://doi.org/10.1002/2015WR017704, 2016.

Boisier, J. P., de Noblet-Ducoudre, N., Pitman, A. J., Cruz, F. T., Delire, C., van den Hurk, B. J. J. M., van der Molen, M. K., Muller, C., and Voldoire, A.: Attributing the impacts of land-cover changes in temperate regions on surface temperature and heat fluxes to specific causes: Results from the first LUCID set of simulations, J. Geophys. Res.-Atmos., 117, D12116, https://doi.org/10.1029/2011JD017106, 2012.

Boisier, J. P., de Noblet-Ducoudré, N., and Ciais, P.: Inferring past land use-induced changes in surface albedo from satellite observations: a useful tool to evaluate model simulations, Biogeosciences, 10, 1501-1516, https://doi.org/10.5194/bg-101501-2013, 2013.

Boone, A. A., Xue, Y., De Salesm, F., Comer, R. E., Hagos, S., Mahanama, S., Schiro, K., Song, G., Wang, G., Li, S., and Mechoso, C. R.: The regional impact of land-use land-cover change (LULCC) over West Africa from and ensemble of global climate models under the auspices of the WAMME2 project, Clim. Dynam., 47, 3547-3573, https://doi.org/10.1007/s00382-016-3252y, 2016.

Boulard, D., Pohl, B., Cretat, J., Vigaud, N., and Pham-Xuan, T.: Downscaling large-scale climate variability using a regional climate model: the case of ENSO over Southern Africa, Clim. Dynam., 40, 1141-1168, https://doi.org/10.1007/s00382-012-14006, 2013.

Bowman, M. S., Soares-Filho, B. S., Merry, F. D., Nepstad, D. C., Rodrigues, H. O., and Almeida, O. T.: Persistence of cattle ranching in the Brazilian Amazon: A spatial analysis of the rationale for beef production, Land Use Policy, 29, 558-568, https://doi.org/10.1016/j.landusepol.2011.09.009, 2012.

Boysen, L. R., Brovkin, V., Arora, V. K., Cadule, P., de NobletDucoudré, N., Kato, E., Pongratz, J., and Gayler, V.: Global and regional effects of land-use change on climate in 21 st century simulations with interactive carbon cycle, Earth Syst. Dynam., 5, 309-319, https://doi.org/10.5194/esd-5-309-2014, 2014.

Breil, M., Rechid, D., Davin, E. L., de Noblet-Ducoudré, N., Katragkou, E., Cardoso, R. M., Hoffmann, P., Jach, L. L., Soares, P. M. M., Sofiadis, G., Strada, S., Strandberg, G., Tölle, M. H., and Warrach-Sagi, K.: The Opposing Effects of Reforestation and Afforestation on the Diurnal Temperature 
Cycle at the Surface and in the Lowest Atmospheric Model Level in the European Summer, J. Climate, 33, 9159-9179, https://doi.org/10.1175/JCLI-D-19-0624.1, 2020.

Bright, R. M.: Metrics for biogeophysical climate forcings from land use and land cover Changes and their inclusion in life cycle assessment: A critical review, Environ. Sci. Technol., 49, 32913303, https://doi.org/10.1021/es505465t, 2015.

Bright, R. M., Eisner, S., Lund, M. T., Majasalmi, T., Myhre, G., and Astrup, R.: Inferring surface albedo prediction error linked to forest structure at high latitudes, J. Geophys. Res.-Atmos., 123, 4910-4925, https://doi.org/10.1029/2018JD028293, 2018.

Burakowski, E. A., Bonan, S. V., Wake, G. B., Dibb, C. P., and Hollinger, J. E.: Evaluating the climate effects of reforestation in New England using a Weather Research and Forecasting (WRF) model multiphysics ensemble, J. Climate, 29, 51415156, https://doi.org/10.1175/JCLI-D-15-0286.1, 2016.

Carlson, K. M., Curran, L. M., Ratnasari, D., Pittman, A. M., Soares-Filho, B. S., Asner, G. P., Trigg, S. N., Gaveau, D. A., Lawrence, D., and Rodrigues, H. O.: Committed carbon emissions, deforestation, and community land conversion from oil palm plantation expansion in West Kalimantan, Indonesia, P. Natl. Acad. Sci. USA, 109, 7559-7564, https://doi.org/10.1073/pnas.1200452109, 2012.

Charney, J. G.: Dynamics of deserts and drought in the Sahel, Q. J. Roy. Meteor. Soc., 101, 193-202, https://doi.org/10.1002/qj.49710142802, 1975.

Chen, F. and Dudhia, J.: Coupling an advanced landsurface/hydrology model with the Penn state/NCAR MM5 modeling system, Part I: model description and implementation, Mon. Weather Rev., 129, 569-585, https://doi.org/10.1175/15200493(2001)129<0569:CAALSH>2.0.CO;2, 2001.

Cheng, L. L., Liu, M., and Zhan, J. Q.: Land use scenario simulation of mountainous districts based on Dinamica EGO model, J. Mt. Sci.-Engl., 17, 289-303, https://doi.org/10.1007/s11629019-5491-y, 2020.

Clough, S. A., Shephard, M. W., Mlawer, J. E., Delamere, J. S., Iacono, M. J., Cady-Pereira, K., Boukabara, S., and Brown, P. D.: Atmospheric radiative transfer modeling: a summary of the AER codes, J. Quant. Spectrosc. Ra., 91, 233-244, https://doi.org/10.1016/j.jqsrt.2004.05.058, 2005.

Collier, P., Conway, G., and Venables, T.: Climate change and Africa, Oxford Rev. Econ. Pol., 24, 337-353, https://doi.org/10.1093/oxrep/grn019, 2008.

Cook, C., Reason, C. J. C., and Hewitson, B. C.: Wet and dry spells within particularly wet and dry summers in the South African summer rainfall region, Climate Res., 26, 17-31, https://doi.org/10.3354/cr026017, 2004.

Cretat, J., Pohl, B., Richard, Y., and Drobinski, P.: Uncertainties in simulating regional climate of Southern Africa: sensitivity to physical parameterizations using WRF, Clim. Dynam., 38, 613634, https://doi.org/10.1007/s00382-011-1055-8, 2012.

Cretat, J., Pohl, B., Dieppois, B., Berthou, S., and Pergaud, J.: The Angola Low: relationship with southern Africa rainfall and ENSO, Clim. Dynam., 52, 1783-1803, https://doi.org/10.1007/s00382-018-4222-3, 2019.

Crossley, J. F., Polcher, J., Cox, P. M., Gedney, N., and Planton, S.: Uncertainties linked to land-surface processes in climate change simulations, Clim. Dynam., 16, 949-961, https://doi.org/10.1007/s003820000092, 2000.
De Almeida, C. M., Monteiro, A. M. V., Soares, G. C. B. S., Cerqueira, G. C., Pennachin, C. L., and Batty, M.: GIS and remote sensing as tools for the simulation of urban land-use change, Int. J. Remote Sens., 26, 759-774, https://doi.org/10.1080/01431160512331316865, 2005.

Dee, D. P., Uppala, S. M., Simmons, A. J., Berrisford, P., Poli, P., Kobayashi, S., Andrae, U., Balmaseda, M. A., Balsamo, G., Bauer, P., Bechtold, P., Beljaars, A. C. M., van de Berg, L., Bidlot, J., Bormann, N., Delsol, C., Dragani, R., Fuentes, M., Geer, A. J., Haimberger, L., Healy, S. B., Hersbach, H., Holm, E. V., Isaksen, L., Kallberg, P., Kohler, M., Matricardi, M., McNally, A. P., Monge-Sanz, B. M., Morcrette, J.-J., Park, B.-K., Peubey, C., de Rosnay, P., Tavolato, C., Thepaut, J.-N., and Vitart, F.: The ERA-Interim reanalysis: configuration and performance of the data assimilation system, Q. J. Roy. Meteor. Soc., 137, 553-597, https://doi.org/10.1002/qj.828, 2011.

Diasso, U. and Abiodun, B. J.: Drought modes in West Africa and how well CORDEX RCMs simulate them, Theor. Appl. Climatol., 128, 223-240, https://doi.org/10.1007/s00704-015-1705-6, 2017.

Diaz, J. P., Gonzalez, A., Exposito, F. J., Perez, J. C., Fernandez, J., Garcia-Diez, M., and Taima, D.: WRF multi-physics simulation of clouds in the African region, Q. J. Roy. Meteor. Soc., 141, 2737-2749, https://doi.org/10.1002/qj.2560, 2015.

Dlugokencky, E. and Tans, P.: Carbon Cycle Greenhouse Gases, NOAA/GML, available at: https://gml.noaa.gov/ccgg/trends/, last access: 5 September 2018.

Duveiller, G., Hooker, J., and Cescatti, A.: The mark of vegetation change on Earth's surface energy balance, Nat. Commun., 9, 679, https://doi.org/10.1038/s41467-017-02810-8, 2018.

Ek, M., Mitchell, K., Lin, Y., Rogers, E., Grunmann, P., Koren, V., Gayno, G., and Tarpley, J.: Implementation of Noah land surface model advances in the National Centers for Environmental Prediction operational mesoscale Eta model, J. Geophys. Res.-Atmos., 108, 8851, https://doi.org/10.1029/2002JD003296, 2003.

Endris, H. S., Lennard, C., Hewitson, B., Dosio, A., Nikulin, G., and Panitz, H.-J.: Teleconnection responses in multi-GCM driven CORDEX RCMs over Eastern Africa, Clim. Dynam., 46, 28212846, https://doi.org/10.1007/s00382-015-2734-7, 2016.

European Centre for Medium-Range Weather Forecasts (ECMWF): ERA-Interim Project, Research Data Archive at the National Center for Atmospheric Research, Computational and Information Systems Laboratory, https://doi.org/10.5065/D6CR5RD9 (last access: 5 October 2018), 2009.

Fita, L., Polcher, J., Giannaros, T. M., Lorenz, T., Milovac, J., Sofiadis, G., Katragkou, E., and Bastin, S.: CORDEX-WRF v1.3: development of a module for the Weather Research and Forecasting (WRF) model to support the CORDEX community, Geosci. Model Dev., 12, 1029-1066, https://doi.org/10.5194/gmd-121029-2019, 2019.

Friedl, M. and Sulla-Menashe, D.: MCD12Q1 MODIS/Terra+Aqua Land Cover Type Yearly L3 Global $500 \mathrm{~m}$ SIN Grid V006, NASA EOSDIS Land Processes DAAC, USA, https://doi.org/10.5067/MODIS/MCD12Q1.006, 2015.

Friedl, M., McIver, D. K., Hodges, J. C. F., Zhang, X. Y., Muchoney, D., Strahler, A. H., Woodcock, C. E., Gopal, S., Schneider, A., Cooper, A., Baccini, A., Gao, F., and Schaaf, C.: Global land cover mapping from MODIS: algo- 
rithms and early results, Remote Sens. Environ., 83, 287-302, https://doi.org/10.1016/S0034-4257(02)00078-0, 2002.

Friedl, M. A., Sulla-Menashe, D., Tan, B., Schneider, A., Ramankutty, N., Sibley, A., and Huang, X. M.: MODIS Collection 5 global land cover: Algorithm refinements and characterization of new datasets, Remote Sens. Environ., 114, 168-182, https://doi.org/10.1016/j.rse.2009.08.016, 2010.

Gbobaniyi, E., Sarr, A., Sylla, M. B., Diallo, I., Lennard, C., Dosio, A., Dhiediou, A., Kamga, A., Klutse, N. A. B., Hewitson, B., Nikulin, G., and Lamptey, B.: Climatology, annual cycle and interannual variability of precipitation and temperature in CORDEX simulations over West Africa, Int. J. Climatol., 34, 2241-2257, https://doi.org/10.1002/joc.3834, 2014.

Ge, J., Qi, J., Lofgren, B. M., Moore, N., Torbick, N., and Olson, J. M.: Impacts of land use/cover classification accuracy on regional climate simulations, J. Geophys. Res.-Atmos., 112, D05107, https://doi.org/10.1029/2006JD007404, 2007.

Ge, J., Qi, J., and Lofgren, B.: Use of vegetation properties from EOS observations for land-climate modeling in East Africa, J. Geophys. Res.-Atmos., 113, D15101, https://doi.org/10.1029/2007JD009628, 2008.

Ghilardi, A., Bailis, R., Mas, J. F., Skutsch, M., Elvir, J. A., Quevedo, A., Masera, O., Dwivedi, P., Drigo, R., and Vega, E.: Spatiotemporal modeling of fuelwood environmental impacts: Towards improved accounting for nonrenewable biomass, Environ. Modell. Softw., 82, 241-254, https://doi.org/10.1016/j.envsoft.2016.04.023, 2016.

Gilliam, G., Pleim, J., and Xiu, A.: Implementation of the PleimXiu Land Surface Model and Asymmetric Convective Model in the WRF Model, in: 8th Annual WRF User's Workshop, Boulder, Colorado, USA, 11-15 June 2007.

Glotfelty, T., Ramirez, D., Bowden, J., Ghilardi, A., and West, J. J.: CLM-AF v 1.0 Code, UNC Dataverse, V1 [code], https://doi.org/10.15139/S3/DZ7XS3, 2020a.

Glotfelty, T., Ramirez, D., Bowden, J., Ghilardi, A., and West, J. J.: CLM-AF Updated Radiation Codes, UNC Dataverse, V1 [code], https://doi.org/10.15139/S3/W2LWJV, 2020b.

Glotfelty, T., Ramirez, D., Bowden, J., Ghilardi, A., and West, J. J.: Default WRF-CLM LAI Output Code, UNC Dataverse, V1 [code], https://doi.org/10.15139/S3/JGIQOE, 2020c.

Glotfelty, T., Ramirez, D., Bowden, J., Ghilardi, A., and West, J. J.: Africa-Bioclimate Regions, UNC Dataverse, V1 [data set], https://doi.org/10.15139/S3/WHNILT, 2020d.

Glotfelty, T., Ramirez, D., Bowden, J., Ghilardi, A., and West, J. J.: MODIS DinamicaEGO Land Use Data, UNC Dataverse, V1 [data set], https://doi.org/10.15139/S3/BEA55Z, 2020e.

Glotfelty, T., Ramirez, D., Bowden, J., Ghilardi, A., and West, J. J.: Overview Information, UNC Dataverse, V1 [data set], https://doi.org/10.15139/S3/MQ8KNS, 2020f.

Gu, H., Jin, J., Wu, Y., Ek, M. B., and Subin, Z. M.: Calibration and validation of lake surface temperature simulations with the coupled WRF-lake model, Climate Change, 129, 471-483, https://doi.org/10.1007/s10584-013-0978-y, 2015.

Hagen, A.: Fuzzy set approach to assessing similarity of categorical maps, Int. J. Geogr. Inf. Sci., 17, 235-249, https://doi.org/10.1080/13658810210157822, 2003.

Hagos, S., Leung, L. R., Xue, Y., Boone, A., de Sales, F., Neupane, N., Huang, M., and Yoon, J.-H.: Assessment of uncertainties in the response of the African monsoon precipitation to land use change simulated by a regional model, Clim. Dynam., 43, 2765 2775, https://doi.org/10.1007/s00382-014-2092-x, 2014.

Harris, I., Jones, P. D., Osborn, T. J., and Lister, D. H.: Updated high-resolution grids of monthly climatic observations - the CRU TS3.10 Dataset, Int. J. Climatol., 34, 623-642, https://doi.org/10.1002/joc.3711, 2014.

Harris, I. C. and Jones, P. D.: CRU TS4.01: Climatic Research Unit (CRU) Time-Series (TS) version 4.01 of high-resolution gridded data of month-by-month variation in climate (Jan. 1901-Dec. 2016), Centre for Environmental Data Analysis, 4 December 2017 [data set], https://doi.org/10.5285/58a8802721c94c66ae45c3baa4d814d0 (last access: 13 November 2020), 2017.

Hartley, A. J., MacBean, N., Georgievski, G., and Bontemps, S.: Uncertainty in plant functional type distributions and its impact on and surface models, Remote Sens. Environ., 203, 71-89, https://doi.org/10.1016/j.rse.2017.07.037, 2017.

Iacono, M. J., Delamere, J. S., Mlawer, E. J., Shephard, M. W., Clough, S. A., and Collins, W. D.: Radiative forcing by long-lived greenhouse gases: Calculations with the AER radiative transfer models, J. Geophys. Res.-Atmos., 113, D13103, https://doi.org/10.1029/2008JD009944, 2008.

Igri, P. M., Tanessong, R. S., Vondou, D. A., Panda, J., Garba, A., Mkankam, F. K., and Kamga, A.: Assessing the performance of the WRF model in predicting high-impact weather conditions over Central and Western Africa: an ensemble-based approach, Nat. Hazards, 93, 1565-1587, https://doi.org/10.1007/s11069018-3368-y, 2018.

Jin, J. and Wen, L.: Evaluation of snowmelt simulations in the Weather Research and Forecasting Model, J. Geophys. Res.Atmos., 117, D10110, https://doi.org/10.1029/2011JD016980, 2012.

Kang, H.-S., Xue, Y., and Collatz, G. J.: Impact assessment of satellite-derived lead area index datasets using a general circulation model, J. Climate, 20, 993-1015, https://doi.org/10.1175/JCLI4054.1, 2007.

Karri, S., Gharai, B., Sai Krishna, S. V. S., and Rao, P. V. N.: Impact of AWiFS derived land cover on simulation of heavy rainfall, in: Proc. SPIE 9882, Remote Sensing and Modeling of the Atmosphere, Oceans, and Interactions VI, SPIE Asia-Pacific Remote Sensing, New Delhi, India, 3 May 2016, 98821M, https://doi.org/10.1117/12.2223627, 2016.

Kerandi, N. M., Laux, P., Arnault, J., and Kunstmann, H.: Performance of the WRF model to simulate the seasonal and interannual variability of hydrometeorological variables in East Africa: a case study for the Tana River basin in Kenya, Theor. Appl. Climatol., 130, 401-418, https://doi.org/10.1007/s00704-016-1890y, 2017.

Kim, J., Waliser, D. E., Mattmann, C. A., Goodale, C. E., Hart, A. F., Zimdars, P. A., Crichton, D. J., Jones, C., Nikulin, G., Hewitson, B., Jack, C., Lennard, C., and Farve, A.: Evaluation of the CORDEX-Africa multi-RCM hindcast: systematic model errors, Clim. Dynam., 42, 1189-1202, https://doi.org/10.1007/s00382013-1751-7, 2014.

Klein, C., Heinzeller, D., Bliefernicht, J., and Kunstmann, H.: Variability of West African monsoon patterns generated by a WRF multi-physics ensemble, Clim. Dynam., 45, 2733-2755, https://doi.org/10.1007/s00382-015-2505-5, 2015. 
Klein, C., Bliefernicht, J., Heinzeller, D., Gessner, U., Klein, I., and Kunstmann, H.: Feedback of observed interannual vegetation change: a regional climate model analysis for the West African monsoon, Clim. Dynam., 48, 2837-2858, https://doi.org/10.1007/s00382-016-3237-x, 2017.

Lamptey, B. L., Barron, E. J., and Pollard, D.: Simulation of the relative impact of land cover and carbon dioxide to climate change from 1700 to 2100, J. Geophys. Res.-Atmos., 110, D20103, https://doi.org/10.1029/2005JD005916, 2005.

Lauer, A. and Hamilton, K.: Simulating clouds with global climate models: a comparison of CMIP5 results with CMIP3 and satellite data, J. Climate, 26, 3833-3845, https://doi.org/10.1175/JCLI-D12-00451.1, 2013.

Lawrence, P. J. and Chase, T. N.: Representing a new MODIS consistent land surface in the Community Land Model (CLM 3.0), J. Geophys. Res.-Biogeo., 112, G01023, https://doi.org/10.1029/2006JG000168, 2007.

Lawrence, P. J. and Chase, T. N.: Climate impacts of making evapotranspiration in the Community Land Model (CLM3) consistent with the Simple Biosphere Model (SiB), J. Hydrometeorol., 10, 374-394, https://doi.org/10.1175/2008JHM987.1, 2009.

Lejeune, Q., Seneviratne, S. I., and Davin, E. L.: Historical landcover change impacts on climate: Comparative assessment of LUCID and CMIP5 multimodel experiments, J. Climate, 30, 1439-1459, https://doi.org/10.1175/JCLI-D-16-0213.1, 2017.

Li, R., Wang, S.-Y., and Gillies, R. R.: Significant impacts of radiation physics in the Weather Research and Forecasting model on the precipitation and dynamics of the West African Monsoon, Clim. Dynam., 44, 1583-1594, https://doi.org/10.1007/s00382014-2294-2, 2015.

Longobardi, P., Montenegro, A., Beltrami, H., and Eby, M.: Deforestation induced climate change: Effects of spatial scale, PLoS ONE, 11, e0153357, https://doi.org/10.1371/journal.pone.0153357, 2016.

$\mathrm{Lu}$, L. and Shuttleworth, W. J.: Incorporating NDVIDerived LAI into the climate versions of RAMS and its impact on regional climate, J. Hydrometeorol., 3, 347-362, https://doi.org/10.1175/15257541(2002)003<0347:INDLIT>2.0.CO;2, 2002.

$\mathrm{Lu}$, Y. and Kueppers, L. M.: Surface energy partitioning over four dominant vegetation types across the United States in a coupled regional climate model (Weather Research and Forecasting Model 3-Community Land Model 3.5), J. Geophys. Res.-Atmos., 117, D06111, https://doi.org/10.1029/2011JD016991, 2012.

Mahmood, R., Pielke, R. A., Hubbard, K. G., Niyogi, D., Dirmeyer, P. A., McAlpine, C., Carleton, A. M., Hale, R., Gameda, S., Beltran-Przekurat, A., Baker, B., McNider, R., Legates, D. R., Shepherd, M., Du, J., Blanken, P. D., Frauenfeld, O. W., Nair, U. S., and Fall, S.: Land cover changes and their biogeophysical effects on climate, Int. J. Climatol., 34, 929-953, https://doi.org/10.1002/joc.3736, 2014.

Mallard, M. S. and Spero, T. L.: Effects of mosaic land use on dynamically downscaled WRF simulations of the contiguous United States, J. Geophys. Res.-Atmos., 124, 9117-9140, https://doi.org/10.1029/2018JD029755, 2019.

Marais, E. A. and Wiedinmyer, C.: Air Quality Impact of Diffuse and Inefficient Combustion Emissions in Africa (DICE-Africa), Environ. Sci. Technol., 50, 10739-10745, https://doi.org/10.1021/acs.est.6b02602, 2016.
Meng, X. H., Evans, J. P., and McCabe, M. F.: The influence of inter-annually varying albedo on regional climate and drought, Clim. Dynam., 42, 787-803, https://doi.org/10.1007/s00382013-1790-0, 2014.

Merry, F., Soares-Filho, B. S., Nepstad, D., Aamacher, G., and Rodrigues, H.: Balancing Conservation and Economic Sustainability: The Future of the Amazon Timber Industry, Environ. Manage., 44, 395-407, https://doi.org/10.1007/s00267-009-9337-1, 2009.

Metzger, M. J., Bunce, R. G. H., Jongman, R. H. G., Sayre, R., Trabucco, A., and Zomer, R.: A high-resolution bioclimate map of the world: a unifying framework for global biodiversity research and monitoring, Global Ecol. Biogeogr., 22, 630-638, https://doi.org/10.1111/geb.12022, 2013.

Moore, N., Torbick, N., Lofgren, B., Wang, J., Pijanowski, B., Andresen, J., Kim, D.-Y., and Olson, J.: Adapting MODIS-derived LAI and fractional cover into the RAMS in East Africa, Int. J. Climatol., 30, 1954-1969, https://doi.org/10.1002/joc.2011, 2010.

Mounkaila, M. S., Abiodun, B. J., and Omotosho, J. B.: Assessing the capability of CORDEX models in simulating onset of rainfall in West Africa, Theor. Appl. Climatol., 119, 255-272, https://doi.org/10.1007/s00704-014-1104-4, 2015.

Mulenga, H. M.: Southern African climatic anomalies, summer rainfall and the Angola low, Dissertation, University of Cape Town, South Africa, 1998.

Munday, C. and Washington, R.: Circulation controls on southern African precipitation in coupled models: The role of the Angola Low, J. Geophys. Res.-Atmos., 122, 861-877, https://doi.org/10.1002/2016JD025736, 2017.

Nakanishi, M. and Niino, H.: An improved Mellor-Yamada level-3 model with condensation physics: its design and verification, Bound.-Lay. Meteorol., 112, 1-31, https://doi.org/10.1023/B:BOUN.0000020164.04146.98, 2004.

Nakanishi, M. and Niino, H.: An improved Mellor-Yamada level-3 model: Its numerical stability and application to a regional prediction of advection fog, Bound.-Lay. Meteorol., 119, 397-407, https://doi.org/10.1007/s10546-005-9030-8, 2006.

NASA/LARC/SD/ASDC: CERES Energy Balanced and Filled (EBAF) Surface Monthly means data in netCDF [Data set], NASA Langley Atmospheric Science Data Center DAAC, https://doi.org/10.5067/TERRA+AQUA/CERES/EBAF-

SURFACE_L3B004.0 (last access: 16 October 2018), 2017a.

NASA/LARC/SD/ASDC: CERES Energy Balanced and Filled (EBAF) TOA Monthly means data in netCDF Edition4.0 [Data set], NASA Langley Atmospheric Science Data Center DAAC, https://doi.org/10.5067/TERRA+AQUA/CERES/EBAFTOA_L3B004.0 (last access: 16 October 2018), 2017 b.

Nepstad, D., Soares-Filho, B. S., Merry, F., Lima, A., Moutinho, P., Carter, J., Bowman, M., Cattaneo, A., Rodrigues, H., Schwartzman, S., Mcgrath, D., Stickler, C., Lubowski, P. P., Rivero, S., Alencar, A., Almeida, O., and Stella, O.: The End of Deforestation in the Brazilian Amazon, Science, 326, 1350-1351, https://doi.org/10.1126/science.1182108, 2009.

Nikulin, G., Jones, C., Giogi, F., Asrar, G., Buchner, M., CerezoMota, R., Christensen, O. B., Deque, M., Fernandez, J., Hansler, A., van Meijgaard, E., Samuelsson, P., Sylla, M. B., and Sushama, L.: Precipitation climatology in an ensemble of 
CORDEX-Africa regional climate simulations, J. Climate, 25, 6057-6078, https://doi.org/10.1175/JCLI-D-11-00375.1, 2012.

Niu, G.-Y. and Yang, Z.-L.: Effects of vegetation canopy processes on snow surface energy and mass balances, J. Geophys. Res.Atmos., 109, D23111, https://doi.org/10.1029/2004JD004884, 2004.

Niu, G.-Y., Yang, Z.-L., Mitchell, K. E., Chen, F., Ek, M. B., Barlage, M., Kumar, A., Manning, K., Niyogi, D., Rosero, E., Tewari, M., and Xia, Y.: The community Noah land surface model with multiparameterization options (Noah-MP): 1. Model description and evaluation with localscale measurements, J. Geophys. Res.-Atmos., 116, D12109, https://doi.org/10.1029/2010JD015139, 2011.

Noble, E., Druyan, L. M., and Fulakeza, M.: The sensitivity of WRF daily summertime simulations over West Africa to alternative parameterizations, Part I: African wave circulation, Mon. Weather Rev., 142, 1588-1608, https://doi.org/10.1175/MWRD-13-00194.1, 2014.

Noble, E., Druyan, L. M., and Fulakeza, M.: The sensitivity of WRF daily summertime simulations over West Africa to alternative parameterizations, Part II: Precipitation, Mon. Weather Rev., 145, 215-233, https://doi.org/10.1175/MWR-D-15-0294.1, 2017.

Nyamweya, C., Desjardins, C., Sigurdsson, S., Tomasson, T., Taabu-Munyaho, A., Sitoki, L., and Stefansson, G.: Simulations of Lake Victoria circulation patterns using the Regional Ocean Modeling System (ROMS), PLoS ONE, 11, e0151272, https://doi.org/10.1371/journal.pone.0151272, 2016.

Odoulami, R. C., Abiodun, B. J., and Ajayi, A. E.: Modelling the potential impacts of afforestation on extreme precipitation over West Africa, Clim. Dynam., 52, 2185-2198, https://doi.org/10.1007/s00382-018-4248-6, 2019.

Oliveira, U., Soares, B., Leitao, R. F. M., and Rodrigues, H. O.: BioDinamica: a toolkit for analyses of biodiversity and biogeography on the Dinamica-EGO modelling platform, Peerj, 7, e7213, https://doi.org/10.7717/Peerj.7213, 2019.

Olsen, K. W., Bonan, G. B., Levis, S., and Vertenstein, M.: Effects of land use change on North American climate: Impact of surface datasets and model biogeophysics, Clim. Dynam., 23, 117-132, https://doi.org/10.1007/s00382-004-0426-9, 2004.

Otieno, V. O. and Anyah, R. O.: Effects of land use changes on climate in the Greater Horn of Africa, Climate Res., 52, 77-95, https://doi.org/10.3354/cr01050, 2012.

Pielke, R. A., Pitman, A., Niyogi, D., Mahmood, R., McAlpine, C., Houssain, F., Goldewijk, K. K., Nair, U., Betts, R., and Fall, S.: Land use/land cover changes and climate: modeling analysis and observational evidence, WIRES Clim. Change, 2, 828-850, https://doi.org/10.1002/wcc.144, 2011.

Platnick, S.: MODIS Atmosphere L3 Monthly Product. NASA MODIS Adaptive Processing System, Goddard Space Flight Center, USA [data set], https://doi.org/10.5067/MODIS/MOD08_M3.061 (last access: 2 October 2020), 2017.

Pleim, J. E. and Xiu, A.: Development of a land surface model, Part II: Data assimiliation, J. Appl. Meteorol. Clim., 42, 1811-1822, https://doi.org/10.1175/15200450(2003)042<1811:DOALSM>2.0.CO;2, 2003.

Pohl, B., Cretat, J., and Camberlin, P.: Testing WRF capability in simulating the atmospheric water cycle over
Equatorial East Africa, Clim. Dynam., 37, 1357-1379, https://doi.org/10.1007/s00382-011-1024-2, 2011.

Quesada, B., Arneth, A., and de Noblet-Ducoudré, N.: Atmospheric, radiative, and hydrologic effects of land use and land cover changes: A global and multimodel picture, J. Geophys. Res.-Atmos., 122, 5113-5131, https://doi.org/10.1002/2016JD025448, 2017.

Ratna, S. B., Ratnam, J. V., Behera, S. K., Rautenbach, C. J. de W., Ndarana, T., Takahashi, K., and Yamagata, T.: Performance assessment of three convective parameterization schemes in WRF for downscaling summer rainfall over South Africa, Clim. Dynam., 42, 2931-2953, https://doi.org/10.1007/s00382-013-19182,2014

Ratnam, J. V., Doi, T., Landman, W. A., and Behera, S. K.: Seasonal Forecasting of Onset of Summer Rains over South Africa, J. Appl. Meteorol. Clim., 57, 2697-2711, https://doi.org/10.1175/JAMC-D-18-0067.1, 2018.

Schaaf, C. B., Gao, F., Strahler, A. H., Lucht, W., Li, X. W., Tsang, T., Strugnell, N. C., Zhang, X. Y., Jin, Y. F., Muller, J. P., Lewis, P., Barnsley, M., Hobson, P., Disney, M., Roberts, G., Dunderdale, M., Doll, C., d'Entremont, R. P., Hu, B. X., Liang, S. L., Privette, J. L., and Roy, D.: First operational BRDF, albedo nadir reflectance products from MODIS, Remote Sens. Environ., 83, 135-148, https://doi.org/10.1016/S0034-4257(02)00091-3, 2002.

Schepanski, K., Knippertz, P., Fiedler, S. Timouk, F., and Demarty, J.: The sensitivity of nocturnal low-level jets and near-surface winds over the Sahel to model resolution, initial conditions and boundary-layer set-up, Q. J. Roy. Meteor. Soc., 141, 1442-1456, https://doi.org/10.1002/qj.2453, 2015.

Sellers, P. J.: Canopy reflectance, photosynthesis and transpiration, Int. J. Remote Sens., 6, 1335-1372, https://doi.org/10.1080/01431168508948283, 1985.

Silvestrini, R. A., Soares-Filho, B. S., Nepstad, D., Coe, M., Rodrigues, H. O., and Assunção, R.: Simulating fire regimes in the Amazon in response to climate change and deforestation, Ecol. Appl., 21, 1573-1590, https://doi.org/10.1890/10-0827.1, 2011.

Skamarock, W. C. and Klemp, J. B.: A time-split nonhydrostatic atmospheric model for weather research and forecasting applications, J. Comput. Phys., 227, 3465-3485, https://doi.org/10.1016/j.jcp.2007.01.037, 2008.

Smirnova, T. G., Brown, J. M., Benjamin, S. G., and Kenyon, J. S.: Modification to the Rapid Update Cycle Land Surface Model (RUC LSM) available in the Weather Research and Forecasting (WRF) Model, Mon. Weather Rev., 144, 1851-1865, https://doi.org/10.1175/MWR-D-15-0198.1, 2016.

Smith, A., Lott, N., and Vose, R.: The Integrated Surface Database: Recent Developments and Partnerships, B. Am. Meteorol. Soc., 92, 704-708, https://doi.org/10.1175/2011BAMS3015.1, 2011.

Smith, M. C., Singarayer, J. S., Valdes, P. J., Kaplan, J. O., and Branch, N. P.: The biogeophysical climatic impacts of anthropogenic land use change during the Holocene, Clim. Past, 12, 923-941, https://doi.org/10.5194/cp-12-923-2016, 2016.

Soares-Filho, B. S., Pennachin, C. L., and Cerqueira, G.: DINAMICA - a stochastic cellular automata model designed to simulate the landscape dynamics in an Amazonian colonization frontier, Ecol. Model., 154, 217-235, https://doi.org/10.1016/S03043800(02)00059-5, 2002. 
Soares-Filho, B. S., Nepstad, D., Curran, L., Voll, E., Cerqueira, G., Garcia, R. A., Ramos, C. A., Mcdonald, A., Lefebvre, P., and Schlesinger, P.: Modeling conservation in the Amazon basin, Nature, 440, 520-523, https://doi.org/10.1038/nature04389, 2006.

Soares-Filho, B. S., Moutinho, P., Nepstad, D., Anderson, A., Rodrigues, H., Garcia, R., Dietzsch, L., Merry, F., Bowman, M., Hissa, L., Silvestrini, R., and Maretti, C.: Role of Brazilian Amazon protected areas in climate change mitigation, P. Natl. Acad. Sci. USA, 107, 10821-10826, https://doi.org/10.1073/pnas.0913048107, 2010.

Spera, S. A., Winter, J. M., and Chipman, J. W.: Evaluation of agricultural land cover representations on regional climate model simulations in the Brazilian Cerrado, J. Geophys. Res.-Atmos., 123, 5163-5176, https://doi.org/10.1029/2017JD027989, 2018.

Subin, Z. M., Riley, W. J., Jin, J., Christianson, D. S., Torn, M. S., and Kueppers, L. M.: Ecosystem feedbacks to climate change in California: Development, Testing, and Analysis Using a Coupled Regional Atmosphere and Land Surface Model (WRF3-CLM3.5), Earth Interact., 15, 1-38, https://doi.org/10.1175/2010EI331.1, 2011.

Subin, Z. M., Riley, W. J., and Mironov, D.: An improved lake model for climate simulations: Model structure, evaluation, and sensitivity analyses in CESM1, J. Adv. Model. Earth Sy., 4, M02001, https://doi.org/10.1029/2011MS000072, 2012.

Sun, S. and Xue, Y.: Implementing a new snow scheme in Simplified Simple Biosphere Model (SSiB), Adv. Atmos. Sci., 18, 335-354, https://doi.org/10.1007/BF02919314, 2001.

Thackeray, C. W., Flectcher, C. G., and Derksen, C.: Diagnosing the impacts of Northern Hemisphere surface albedo on simulated climate, J. Climate, 32, 1777-1795, https://doi.org/10.1175/JCLID-18-0083.1, 2019.

Thapa, R. B. and Murayama, Y.: Urban growth modeling of Kathmandu metropolitan region, Nepal, Comput. Environ. Urban, 35, 25-34, https://doi.org/10.1016/j.compenvurbsys.2010.07.005, 2011.

Thompson, G. and Eidhammer, T.: A study of aerosol impacts on clouds and precipitation development in a large winter cyclone, J. Atmos. Sci., 71, 3636-3658, https://doi.org/10.1175/JAS-D-130305.1, 2014.

Thomson, E. R., Malhi, Y., Bartholomeus, H., Oliveras, I., Gvozdevaite, A., Abraham, A. J., Herold, M., Adu-Bredu, S., and Doughty, C. E.: Mapping the leaf economic spectrum across West African tropical forests using UAVacquired hyperspectral imagery, Remote Sens.-Basel, 10, 1532, https://doi.org/10.3390/rs10101532, 2018.

Tian, Y., Dickinson, R. E., Zhou, L., Zeng, Z., Dai, Y., Myneni, R. B., Knyazikhin, Y., Zhang, Z., Friedl, M., Yu, H., Wu, W., and Shaikh, M.: Comparison of seasonal and spatial variations of leaf area index and fraction of absorbed photosynthetically active radiation from Moderate Resolution Imaging Spectroradiometer (MODIS) and Common Land Model, J. Geophys. Res.-Atmos., 109, D01103, https://doi.org/10.1029/2003JD003777, 2004a.

Tian, Y., Dickinson, R. E., Zhou, L., and Shaikh, M.: Impact of new land boundary conditions from Moderate Resolution Imaging Spectroradiometer (MODIS) data on the climatology of land surface variables, J. Geophys. Res.-Atmos., 109, D20115, https://doi.org/10.1029/2003JD004499, 2004b.

Towns, J., Cockerill, T., Dahan, M., Foster, I., Gaither, K., Grimshaw, A., Hazlewood, V., Lathrop, S., Lifka, D., Peterson,
G. D., Roskies, R., Scott, J. R., and Wilkins-Diehr, N.: XSEDE: Accelerating Scientific Discovery, Comput. Sci. Eng., 16, 62-74, https://doi.org/10.1109/MCSE.2014.80, 2014.

Tropical Rainfall Measuring Mission (TRMM): TRMM (TMPA) Rainfall Estimate L3 3 hour 0.25 degree $x \quad 0.25$ degree V7, Greenbelt, MD, Goddard Earth Sciences Data and Information Services Center (GES DISC) [data set], https://doi.org/10.5067/TRMM/TMPA/3H/7 (last access: 27 November 2018), 2011.

UNSD: Standard Country or Area Codes for Statistics Use, 1999 (Revision 4), United Nations, New York, USA, available at: https://unstats.un.org/unsd/methodology/m49/ (last access: 24 May 2021), 1999.

Wang, G., Yu, M., and Xue, Y.: Modeling the potential contribution of land cover changes to the late twentieth century Sahel drought using a regional climate model: impact of lateral boundary conditions, Clim. Dynam., 47, 3457-3477, https://doi.org/10.1007/s00382-015-2812-x, 2016.

Wang, G., Ahmed, K. F., You, L., Yu, M., Pal, J., and Li, Z.: Projecting regional climate and cropland changes using a linked biogeophysical-socioeconomic modeling framework: 1. Model description and an equilibrium application over West Africa, J. Adv. Model. Earth Sy., 9, 354-376, https://doi.org/10.1002/2016MS000712, 2017.

Wang, Z., Zeng, X., Barlage, M., Dickenson, R. E., Gao, F., and Schaaf, C. B.: Using MODIS BRDF and albedo data to evaluate global model land surface albedo, J. Hydrometeorol., 5, 3-14, https://doi.org/10.1175/15257541(2004)005<0003:UMBAAD>2.0.CO;2, 2004.

Winckler, J., Reick, C. H., Luyssaert, S., Cescatti, A., Stoy, P. C., Lejeune, Q., Raddatz, T., Chlond, A., Heidkamp, M., and Pongratz, J.: Different response of surface temperature and air temperature to deforestation in climate models, Earth Syst. Dynam., 10, 473-484, https://doi.org/10.5194/esd-10-473-2019, 2019.

Vigaud, N., Roucou, P., Fontaine, B., Sijikumar, S., and Tyteca, S.: WRF/APPEGE-CLIMAT simulated climate trends over West Africa, Clim. Dynam., 36, 925-944, https://doi.org/10.1007/s00382-009-0707-4, 2011.

Xia, Y., Mocko, D., Huang, M., Li, B., Rodell, M., Mitchell, K. E., Cai, X., and Ek, M. B.: Comparison and assessment of three advanced land surface models in simulating terrestrial water storage components over the United States, J. Hydrometeorol., 18, 625-649, https://doi.org/10.1175/JHM-D-16-0112.1, 2017.

Xue, T. and Shukla, J.: The influence of land surface properties on Sahel Climate, Part 1: Desertification, J. Climate, 6, 2232-2245, https://doi.org/10.1175/15200442(1993)006<2232:TIOLSP>2.0.CO;2, 1993.

Xue, Y., Sellers, P. J., Kinter, J. L., and Shukla, J.: A Simplified Biosphere Model for Global Climate Studies, J. Climate, 4, 345-164, https://doi.org/10.1175/15200442(1991)004<0345:ASBMFG>2.0.CO;2, 1991.

Xue, Y., De Sales, F., Lau, W. K.-M., Boone, A., Kim, K.-M., Mechoso, C. R., Wang, G., Kucharski, F., Schiro, K., Hosaka, M., Li, S., Druyan, L. M., Sanda, I. S., Thiaw, W., and Zeng, N.: West African monsoon decadal variability and surface related forcing: second West African Monsoon Modeling and Evaluation Project Experiment (WAMME II), Clim. Dynam., 47, 35173545, https://doi.org/10.1007/s00382-016-3224-2, 2016. 
Yang, R. and Friedl, M. A.: Modeling the effects of threedimensional vegetation structure on surface radiation and energy balance in boreal forests, J. Geophys. Res.-Atmos., 108, 8615, https://doi.org/10.1029/2002JD003109, 2003.

Yi, W., Gao, Z. Q., Li, Z. H., and Chen, M. S.: Land-use and land-cover sceneries in China: an application of Dinamica EGO model, in: Proc. SPIE 8513, SPIE Optical Engineering + Applications, Remote Sensing and Modeling of Ecosystems for Sustainability IX, San Diego, California, USA, 12-16 August 2012, 85130I, https://doi.org/10.1117/12.927782, 2012.

Zhang, C., Wang, Y., and Hamilton, K.: Improved representation of boundary layer clouds over the Southeast Pacific in ARW-WRF using a modified Tiedtke cumulus parameterization scheme, Mon. Weather Rev., 139, 3489-3513, https://doi.org/10.1175/MWR-D-10-05091.1, 2011.
Zhang, M., Lee, X., Yu, G., Han, S., Wang, H., Yan, J., Zhang, Y., Li, Y., Ohta, T., Hirano, T., Kim, J., Yoshifuji, N., and Wang, W.: Response of surface air temperature to small-scale land clearing across latitudes, Environ. Res. Lett., 9, 034003, https://doi.org/10.1088/1748-9326/9/3/034002, 2014.

Zhao, M. and Pitman, A. J.: The regional scale impact of land cover change simulated with a climate model, Int. J. Climatol., 22, 271-290, https://doi.org/10.1002/joc.727, 2002.

Zheng, Y., Kumar, A., and Niyogi, D.: Impacts of land-atmosphere coupling on regional rainfall and convection, Clim. Dynam., 44, 2383-2409, https://doi.org/10.1007/s00382-014-2442-8, 2015. 